\title{
Typology of pentad circulation anomalies over the Eastern Africa-Western Indian Ocean region, and their relationship with rainfall
}

\author{
Benjamin Pohl*, Pierre Camberlin, Pascal Roucou \\ Centre de Recherches de Climatologie, Université de Bourgogne, BP 27877, 21078 Dijon, France
}

\begin{abstract}
The aim of this study was to classify the most frequently observed atmospheric circulation anomaly patterns in eastern Africa and the adjacent Indian Ocean. As an example of the usefulness of such a classification, the second objective was to test whether these patterns account for intraseasonal rainfall anomalies in the region. A partitioning algorithm, known as dynamical cluster analysis, was therefore applied to the zonal $(U)$ and meridional $(V)$ components of the wind anomalies, obtained from the NCEP-NCAR Reanalysis R-2 at the pentad ( 5 d) timescale. The 3 geopotential levels 850, 700 and $200 \mathrm{hPa}$ were combined. Focus is on the transition seasons (March to May and October to December), which correspond to the 2 East African rainy seasons. The classification domain is large enough $\left(40^{\circ}\right.$ latitude $\times 40^{\circ}$ longitude) to describe large-scale anomaly patterns, but it focuses on equatorial and subequatorial atmospheric dynamics. The results consist of 7 major wind anomaly clusters, for which associated atmospheric fields (geopotential height anomalies, precipitation anomalies) and the seasonal distribution were explored. Among them, 2 clusters strongly resemble the anomaly patterns associated with the Madden-Julian Oscillation. The other major configurations show similarities with recurrent previously observed patterns involved in wet or dry spells over East or Southern Africa. Statistical tests reveal that this partition is able to significantly discriminate rainfall anomalies over the eastern part of the African continent; 4 of the 7 clusters correspond to abnormally wet or dry events over Equatorial East Africa.
\end{abstract}

KEY WORDS: Dynamical cluster analysis - Eastern Africa - Intraseasonal rainfall variability Circulation anomaly patterns $\cdot$ Madden-Julian Oscillation

\section{INTRODUCTION}

The classification of atmospheric circulation patterns has been for decades a focus in climatology. Most of the attempts have concentrated on the mid-latitudes, while the tropics were neglected. In Equatorial East Africa (EEA) in particular, there is still limited knowledge of the way circulation patterns are demarcated from each other, and of the possible clustering of these patterns around a few recurrent types.

Previous studies (Johnson \& Mörth 1960, Sissons 1966, Okoola 1999a,b) depicted pentad and daily (synoptic scale) circulation patterns around EEA, but their approach was mainly based on case studies. Only
Johnson \& Mörth (1960) tried to classify empirically the most frequently observed atmospheric configurations; their work was essentially based on their experience in synoptical meteorology. The current availability of new datasets, the reanalyses, at the daily timescale and on a worldwide $2.5^{\circ} \times 2.5^{\circ}$ regular grid, makes it possible to apply objective partitioning methods in order to obtain consistent atmospheric configuration types. The determination of the most recurrent atmospheric patterns obtained by a systematic process may also help to renew and to complement these empirical studies. This study applied a statistical algorithm, known as dynamical cluster analysis, to atmospheric circulation anomaly patterns, in order to obtain an 
objective partitioning of pentad circulation for a $20 \mathrm{yr}$ period. This methodology has already been used for several climatological analyses (e.g. Desbois et al. 1982, Michelangeli et al. 1995, Moron \& Plaut 2003). However, this study constitutes the first application of such an algorithm to atmospheric fields inside the tropical belt.

Such a typology of wind patterns may present some interest for downscaling applications (e.g. the projection of the simulated wind fields at the end of the 21st century under enhanced greenhouse-effect conditions). It is also of major interest for the understanding of rainfall variability.

Large areas in the eastern part of the African continent experience dry climatic conditions. Water resource variability strongly impacts major sectors of the economy, such as agriculture (maize production, cotton, tea and coffee plantations, or extensive cattle breeding), and adequate rainfall amounts are a key requirement for much of the rural population. It is therefore highly important to better understand the meteorological phenomena involved in abnormally high or low precipitation amounts. The EEA region experiences a bimodal annual cycle: the 2 rainy seasons correspond to the meridional migrations of the Inter-Tropical Convergence Zone (ITCZ), and extend from March to May (MAM) and from October to December (OND). Each of them is marked by a relatively high interannual variability, i.e. the seasonal rainfall amounts may vary highly from one year to another. Large-scale teleconnection patterns are clearly found for the OND season (e.g. Beltrando \& Cadet 1990, Black et al. 2003), and recent studies suggest that interannual variability is the result of intraseasonal fluctuations occurring during the East African rainy seasons. Each 3 mo long rainy season is generally characterized by the alternation of 3 to 4 marked, 5 to $10 \mathrm{~d}$ long rainy spells, liable to bring most of the cumulative precipitations amounts, and relatively dry phases occurring between 2 consecutive wet periods (Kabanda \& Jury 2000, Mpeta \& Jury 2001, Camberlin \& Okoola 2003). This suggests that comprehension of intra-seasonal rainfall variability may help in understanding interannual variability. Moreover, understanding the temporal precipitation distribution inside a season is as fundamentally important for agricultural yields as seasonal rainfall totals. Rainfall variability is generally approached through correlation or composite analyses, which are adequate if the relationship between rainfall and atmospheric circulation is fairly simple and more or less linear, but less than adequate if 2 different circulation patterns lead to similar precipitation anomalies. In order to emphasize the usefulness of the classification, focus here is given to rainfall applications. A classification of wind anomaly pat- terns may help to clarify the recurrent atmospheric configurations observed over the region, and their possible relations with such intraseasonal rainfall fluctuations.

The aim of this study was to identify recurrent largescale circulation anomaly patterns over the eastern part of the African continent and the adjacent Indian Ocean. The corresponding rainfall anomaly patterns were then analysed. The objective was thus to clarify whether dry and wet anomalies observed in the equatorial regions located on the East African meridian fit into a limited number of discrete and spatially consistent large-scale wind anomaly patterns. The approach is original in that, in contrast to previous studies that usually started with the identification of wet/dry events and then analysed simultaneous large-scale atmospheric anomaly patterns, it first defines the most recurrent patterns of atmospheric variability during the 2 EEA rainy seasons (MAM and OND). The following section presents the data used for this study. Section 3 depicts the dynamical cluster analysis algorithm. Section 4 presents the main results, based on maps. Those results are then discussed in Section 5.

\section{DATA}

This study makes use of the National Centre for Environmental Prediction-Department of Energy (NCEP-DOE) Atmospheric Model Intercomparison Project (AMIP-II) Reanalysis (R-2) fields (Kalnay et al. 1996, Kanamitsu et al. 2002). The spatial resolution is $2.5^{\circ} \times 2.5^{\circ}$ horizontally, interpolated on 28 vertical levels (from 1000 to $10 \mathrm{hPa}$ ), and the period of availability begins in January 1979. The dataset is an update of the NCEP-NCAR reanalysis, featuring newer physics and observed soil-moisture forcing, and eliminates several previous errors. Many researchers, including Mutai \& Ward (2000), Camberlin \& Philippon (2002), Zorita \& Tilya (2002) among others, have used this dataset for studies on the region. This study uses the geopotential height and the zonal $(U)$, meridional $(V)$ and vertical $(\omega)$ components of the wind (considered as 'most reliable' variables, except for the latter; Kalnay et al. 1996). Fig. 1 depicts, for the 3 levels 850, 700 and 200 $\mathrm{hPa}$, the maps of mean wind fields for MAM and OND. Though the classification itself is applied on the smaller area of the box in Fig. 1, all maps are plotted for an extended domain $\left(30^{\circ} \mathrm{N}-30^{\circ} \mathrm{S}, 10-70^{\circ} \mathrm{E}\right)$ in order to show the larger-scale patterns in which the regional circulation is embedded. Some of the major characteristics of the global circulation of the transition periods between the boreal and austral summer monsoons clearly appear (Fig. 1), such as the northern and the southern trade winds in the lower levels (850 and 

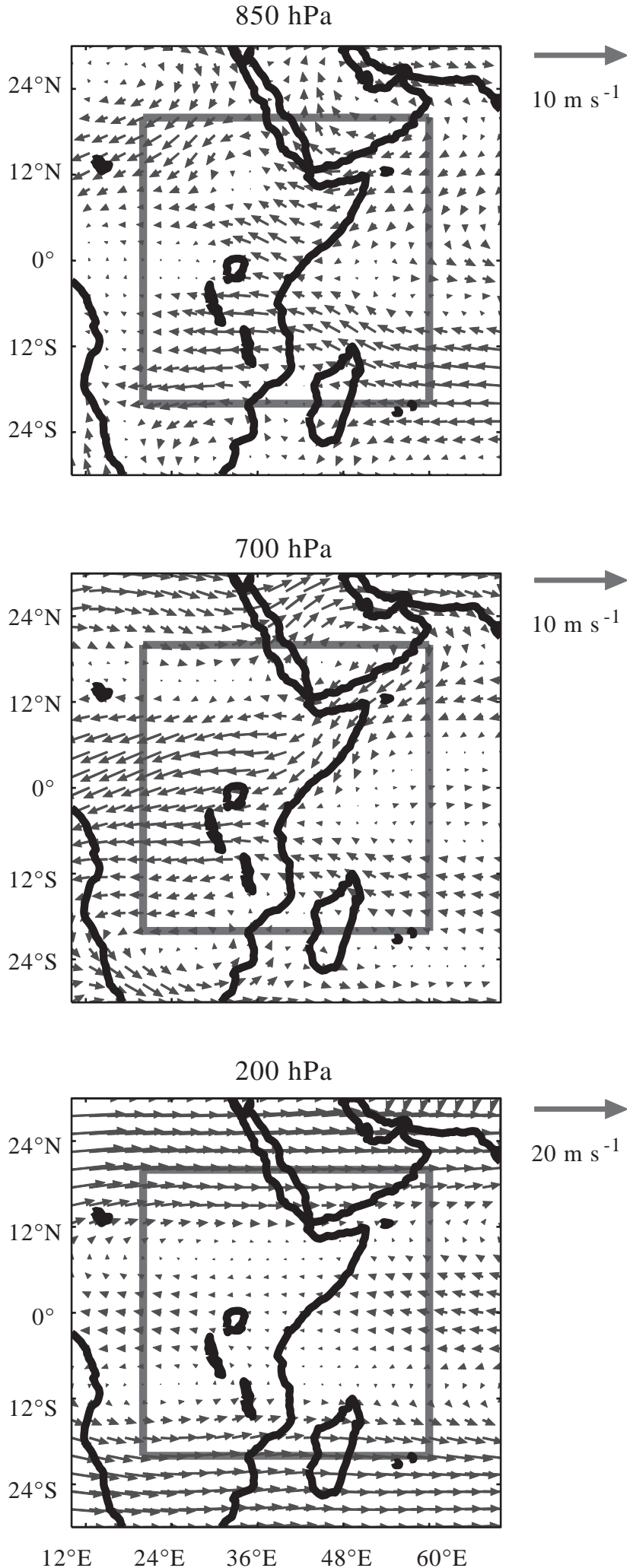

$700 \mathrm{hPa}$ ) and the mid-latitude westerlies at $200 \mathrm{hPa}$. On average, a belt of low-latitude westerlies appears over the Central Indian Ocean at $850 \mathrm{hPa}$. These winds are mostly observed during OND, when the Indian Walker cell is strongly developed over these longitudes (Hastenrath 2000). The following cluster analysis will concern anomaly fields, and the real circulation will not be considered. Fig. 1 is then (approximately) the mean situation, with respect to which the anomaly fields are calculated. However, it should be remembered that the mean fields significantly evolve during MAM and OND: the reference to the fields presented on Fig. 1 is therefore relative.

The GPCP (Global Precipitation Climatology Project; Huffman et al. 1995, 1997) dataset was used to approximate 5 d rainfall amounts over the African continent and the nearby Indian Ocean. The GPCP algorithm merges satellite data and worldwide rainfall observations to approximate precipitation, on both land and sea areas. The data are available from January 1979 until today on a $2.5^{\circ} \times 2.5^{\circ}$ regular grid. Their reliability has been controlled and discussed by Gruber et al. (2000).

The intraseasonal oscillation was extracted using the multivariate Madden-Julian Oscillation (MJO) indices developed by Wheeler \& Hendon (2004) and based on a principal component analysis (PCA) applied to largescale daily patterns of 850 and $200 \mathrm{hPa}$ zonal wind and outgoing longwave radiation (OLR) at $15^{\circ} \mathrm{N}$ to $15^{\circ} \mathrm{S}$. A pair of indices was obtained corresponding to the 2 first principal components and describing the MJOrelated large-scale circulation and convection eastward propagation (Madden \& Julian 1994, Matthews 2000). The oscillation was finally decomposed into its phases (i.e. an angle measurement depending on the location of the enhanced convection cells within the tropics) and its activity (i.e. a distance measurement indicating the strength of the intraseasonal signal).

\section{METHODOLOGY: DYNAMICAL CLUSTER ALGORITHM}

The automatic classification of the atmospheric circulation anomaly patterns over the eastern part of Africa and the western Indian Ocean was carried out by applying a non-hierarchical sample-partitioning algorithm, hereafter referred to as cluster analysis (Michelangeli et al. 1995).

Cluster analysis has been used in meteorology to classify clouds into coherent types (Desbois et al. 1982) and in climatology to determine the recurrence and the quasi-stationarity of weather regimes over the Atlantic and Pacific Ocean Basins (Michelangeli et al. 1995). It has also been used to investigate the influence

Fig. 1. Mean circulation $\left(\mathrm{m} \mathrm{s}^{-1}\right)$ for March to May (MAM) and October to December (OND), 1979-2002. The classification domain is shown by the box 
of sea-surface temperature (SST) anomalies in the equatorial Pacific basin on the probability of occurrence of weather regimes over the North Atlantic Ocean (Moron \& Plaut 2003). Huth (1996) concluded that the algorithm leads to spatially and temporally quite consistent partitions and to similar size clusters (types) that are well separated from each other.

The cluster analysis algorithm must be applied after a data reduction process, in order to ensure the linear independence of the input data (Huth 1996). If the algorithm is directly applied to at least partially linearly dependent variables, the final result may be significantly affected because of the more important influence of the correlated variables on the obtained partitioning. The classification itself is preceded by a PCA based on the correlation matrix (see Section 3.3). The variables are the NCEP zonal $(U)$ and meridional $(V)$ components of the wind at each grid point, and the observations are the pentads (5 d) in MAM and OND for 1979-2002. The PCA converts the initial variables into a series of empirical orthogonal functions (EOFs) statistically independent from each other, which still explain a major part of the initial variance.

\subsection{Dynamical cluster algorithm formulation}

Cheng \& Wallace (1993) and Michelangeli et al. (1995) contributed to complete the dynamical cluster algorithm; the presentation of the methodology is therefore essentially inspired by their studies. It is presented here for a better understanding of its specificities.

Given a previously fixed number of clusters, $k$, the aim of the cluster analysis algorithm is to obtain a partition, $P$, of the observations (pentads) into $k$ clusters that minimizes the sum of the intra-cluster variances, $W$. The Euclidian distance is used to measure the similarity between 2 observations, $X$ and $Y$. The overall minimum of the function $W(P)$ corresponds then to the partition that best separates the different points. When the classification is applied to large samples, climatological series for example, this overall minimum cannot be found in practice, because of the huge number of different possibilities to explore. The algorithm defines $n$ iterative partitions, $P^{(n)}$, for which $W\left(P^{(n)}\right)$ decreases with $n$ and eventually converges to a local minimum of the function, $W(P)$. The overall minimum of $W(P)$ is surrounded by many local minima that differ from it by only a few observations, exchanged from one cluster to another, and essentially found at the periphery of them. The latter may largely depend on the analysed sample, the algorithm being initialized by a random draw of the $k$ clusters. The reproducibility of the obtained partitions should therefore be tested.
Initialization of the algorithm. $k$ points are first randomly chosen as initial cluster centres among all data; they are then used as the initial centroids of the $k$ clusters of the first partition $P^{0}$ in order to initialize the algorithm.

Iteration $i-1$ to $i$. Using the $k$ centroids, $Y^{(i-1)}$, of the partition $P^{(i-1)}$, each pentad from the original dataset is assigned to the nearest centroid, $Y^{(i-1)}$, the similarity between each pentad and each centroid being measured by the Euclidian distance. A new partition, $P^{(i)}$, is then obtained, for which the $k$ centroids, $Y^{(i)}$, of the $k$ clusters are recomputed. For each iteration, the sum of the intra-cluster variances, $W\left(P^{(i)}\right)$, is calculated.

End criterion. The algorithm stops when $W\left(P^{(i)}\right)$ has converged to a minimum, i.e. when an additional iteration does not significantly affect the partition any more. On average, the convergence is obtained before 50 iterations.

\subsection{Similarity of two partitions and reproducibility}

If the distribution of the climatological dataset is uniform, the final partition is assumed to be largely dependent on the initial randomly chosen seeds. In contrast, when the dataset is distributed into welldefined clusters, 2 different initial draws should theoretically lead to roughly similar final partitions. The dependence of the final result on the initial random draw may thus be used as an indicator of the degree of classifiability of the dataset into $k$ clusters.

The robustness of the final partition will be determined using 3 criteria: (1) Is this partition the best one that can be found, given a fixed number of clusters $k$ ? (2) What is the most appropriate value for $k$ ? (3) Are the final clusters reproducible from different initial random draws?

Following Michelangeli et al. (1995) and Moron \& Plaut (2003), we performed 50 different partitions of the wind anomaly patterns, each time initialized by a different random draw. The most natural way to measure the dependence of the final partition on the initial random draw, and thus the classifiability of the original dataset, consists of comparing several final partitions for a given number of clusters $k$. We then retain the partition having the highest mean similarity with the 49 other ones. A classifiability index, $C^{*}$ (Cheng \& Wallace 1993), is next defined, which measures the average similarity within the 50 sets of clusters: its value would be exactly 1 if all the partitions were identical. If the wind anomaly patterns gather into $k$ clusters in a natural way, one would expect the classifiability of the actual maps to be significantly better than that of an ensemble of artificial datasets generated through a first-order Markov process having the same covari- 
ance matrix as the true atmospheric data (Moron \& Plaut 2003). The red-noise test (applied to Markovgenerated red-noise data) operates as follows: 100 samples of the same length as the atmospheric dataset are generated, providing 100 values of the classifiability index, which are ranked to find the 10 and $90 \%$ confidence limits. The value of $C^{*}$ for the atmospheric dataset is then compared with these limits: a value above the $90 \%$ confidence limit indicates, for the corresponding value of $k$, a classifiability significantly higher than that of the red-noise model. The operation is repeated for $k$ varying from 3 to 10: in most cases the best choice for the number of clusters appears quite unambiguously.

\subsection{Application of the dynamical cluster algorithm}

The atmospheric circulation is described by the $U$ and $V$ components of the wind fields, obtained from the NCEP-DOE R-2 reanalysis daily dataset. We first attempted to classify atmospheric configurations based on geopotential height standardized anomalies, but the result was strongly dependent on the large-scale tropospheric heating following El Niño events.

Daily data were averaged to pentad data in order to be compatible with the GPCP time step, which is still fully adequate for intraseasonal variability surveys (Kabanda \& Jury 2000, Mpeta \& Jury 2001). Finally, the study includes Pentads 13 to 30 (MAM) and 56 to 73 (OND), because they constitute the wettest periods for much of EEA. The consistency of anomaly patterns between MAM and OND was tested by applying separate classifications for the 2 seasons (not shown).

The classification was applied on the circulation anomalies after removal of the annual cycle in order to eliminate the variance associated with the shift of the ITCZ. Besides, the aim was not to classify the observed wind fields themselves but to determine the most recurrent anomaly patterns within the region. The $U$ and $V$ wind anomalies were standardized (variance $=1$ for each grid point of each level for MAM + OND 1979-2002) in order to attribute the same weight to upper-layer and lower-layer anomalies (the former usually concentrate more variance than the latter, the strongest and most spatially coherent signals occurring in the upper troposphere). In the final results, meridional anomalies will therefore have the same weight on cluster determination as the zonal fields. Without standardization this situation would not have occurred, because $U$ is generally characterized by larger and spatially more coherent anomalies.

As stated above, the signals were then captured and synthesized by a single PCA (applied on the 3 levels and on all the grid points), on which the classification

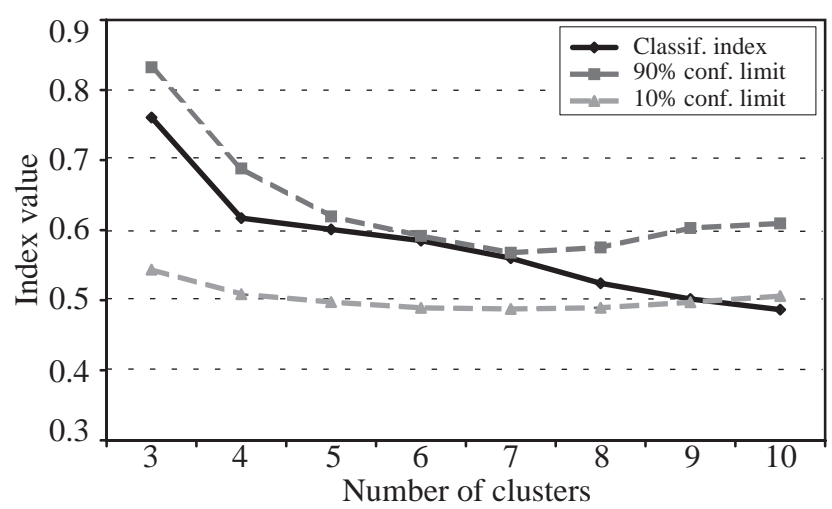

Fig. 2. Series of classifiability indices for a number of clusters, $k$, varying from 3 to $10 ; 10$ and $90 \%$ confidence limits, obtained from the Markov noise-generating process, are shown as dashed lines

itself was implemented. The circulation-anomaly classified area is delimited by the bounds $20^{\circ} \mathrm{N}-20^{\circ} \mathrm{S}$, $20-60^{\circ} \mathrm{E}$, using simultaneously the 3 geopotential levels 850, 700 and $200 \mathrm{hPa}$. The latitudinal extent was chosen in order to exclude purely extra-tropical signals, characterized by a strong variability that could have altered the final partition, and to document atmospheric patterns over a large area around EEA. As a preparatory work, a series of classifications led to a precise delimitation of the retained domain (not shown). Other tentative classifications similarly helped to select the atmospheric levels. The 3 geopotential levels were chosen to synthetically integrate lower, higher and mid-level circulation. These levels also appear adequate in describing the main features of the regional atmospheric circulation (Camberlin \& Wairoto 1997, Okoola 1999a,b, Mutai \& Ward 2000), including those related to mid-latitude systems (Johnson \& Mörth 1960) or to the large-scale zonal anomaly cells along the equator, at both the intraseasonal timescale (MJO; Madden \& Julian 1994, Kiladis \& Weickmann 1997, Wheeler \& Hendon 2004) and the interannual timescale (Indian Walker cell; Hastenrath 2000). The use of the $700 \mathrm{hPa}$ level improved the statistical significance of the final classification, estimated by computing the classifiability index (Fig. 2); it also deliberately allocates to lower and mid-levels, of great interest with regard to rainfall-inducing processes, a stronger impact on the final partition.

In short, the dynamical cluster analysis was applied to $U$ and $V$ standardized circulation anomalies at 850 , 700 and $200 \mathrm{hPa}$, after removal of the annual cycle for each grid point included in the area $20^{\circ} \mathrm{N}-20^{\circ} \mathrm{S}$, $20-60^{\circ} \mathrm{E}$. However, the results are presented on an extended domain in order to examine large-scale patterns; the choice of the study area allows one to isolate equatorial and tropical atmospheric signals. 
a) Wind anomalies $\left(\mathrm{m} \mathrm{s}^{-1}\right)$

b) ANOVA between rainfall estimates

Cluster 1
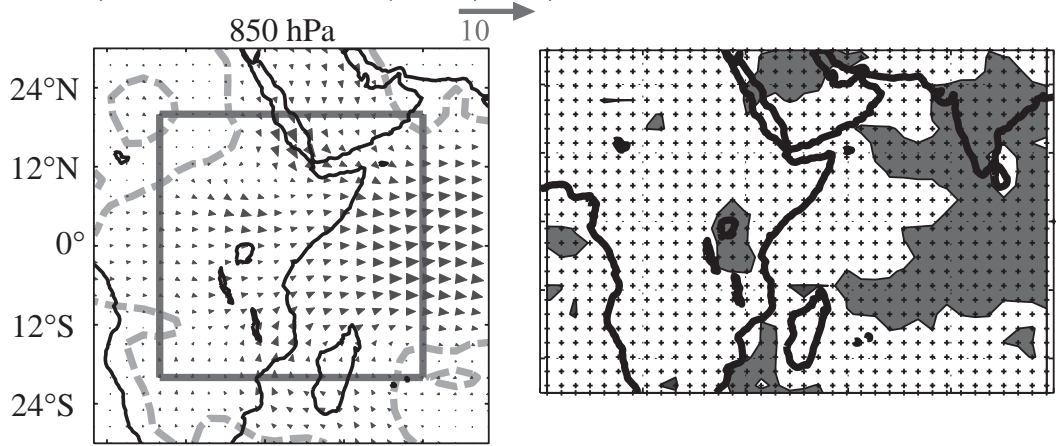

c) Geopotential height anomalies
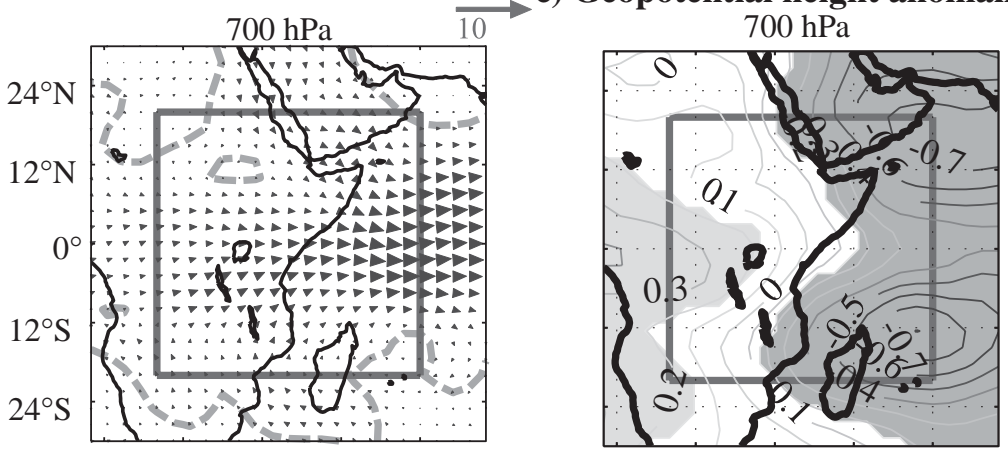

d) GPCP-estimated rainfall anomalies

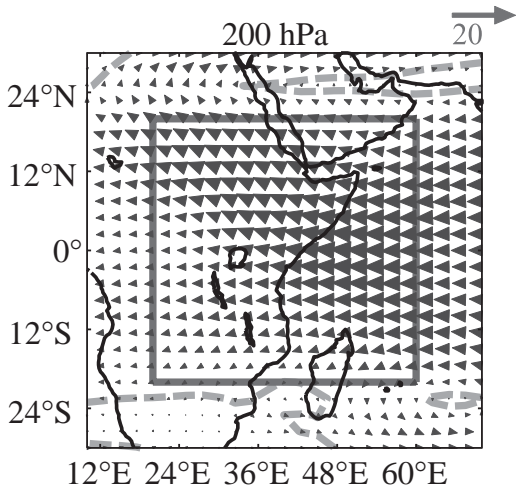

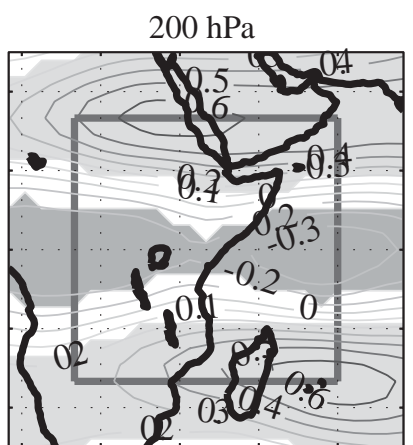

$12^{\circ} \mathrm{E} 24^{\circ} \mathrm{E} 36^{\circ} \mathrm{E} 48^{\circ} \mathrm{E} 60^{\circ} \mathrm{E}$

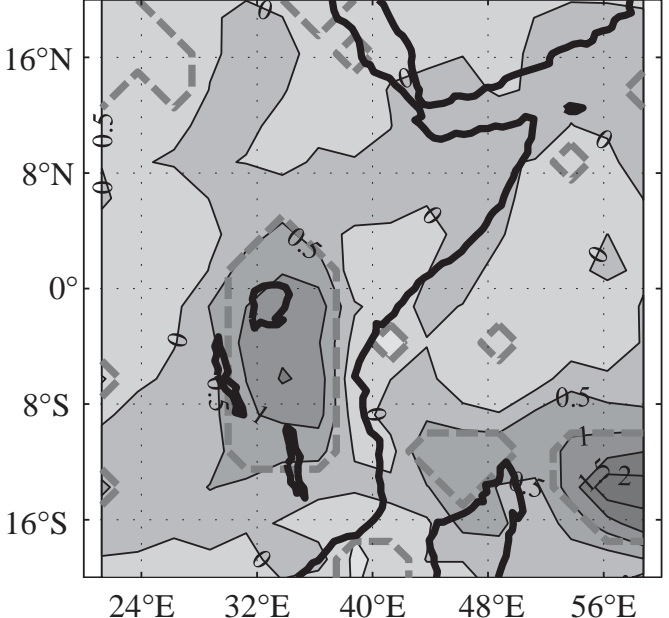

e) Seasonal distribution

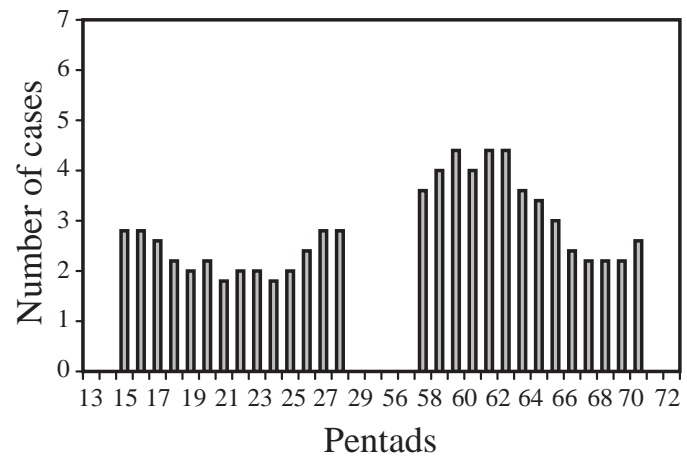

Fig. 3. Cluster 1, wind anomalies. All anomalies are calculated after removal of the annual cycle. (a) Wind anomalies (m $\mathrm{s}^{-1}$ ); dashed lines encompass significant anomalies (Hotelling $t^{2}$-test, 95\% level). (b) ANOVA between the cluster and GPCPestimated rainfall anomalies; shaded areas show the regions where the cluster significantly discriminates rainfall (95\% level). (c) Geopotential height standardized anomalies; shaded areas show significant anomalies ( $t$-test, $95 \%$ level): dark grey-negative, light grey-positive. (d) GPCP-estimated rainfall anomalies $\left(\mathrm{mm} \mathrm{d}^{-1}\right)$; dashed lines encompass significant anomalies ( $t$-test, 95\% level). (e) Seasonal distribution; analysed pentads (MAM, pentads 13 to 30; OND, pentads 56 to 73 ) are on the $x$-axis, and number of occurrences in 1979-2002 on the $y$-axis; results were filtered using a 3-pentad moving average

\section{RESULTS}

\subsection{Determination of the number of clusters}

The best choice for the number of clusters $k$ may be indicated by the computation of the classifiability index, and its comparison with the same index calculated on the red-noise-generated signal. It appears in Fig. 2 that the values are generally far below the confidence bounds, indicating a poor degree of reliability. However, values of $k$ between 5 and 7 show the overall best results, and they reach the $90 \%$ confidence bound. Partitions into 5 , 6 and 7 clusters were therefore examined more closely, as they led to the most coherent clusters. The anomaly fields obtained for $k=7$ were seen to display spatial patterns closer to some of those described in previous studies (Johnson \& Mörth 1960, Okoola 1999a,b). A partition into 7 clusters was thus finally retained. 
a) Wind anomalies ( $\left.\mathrm{m} \mathrm{s}^{-1}\right)$
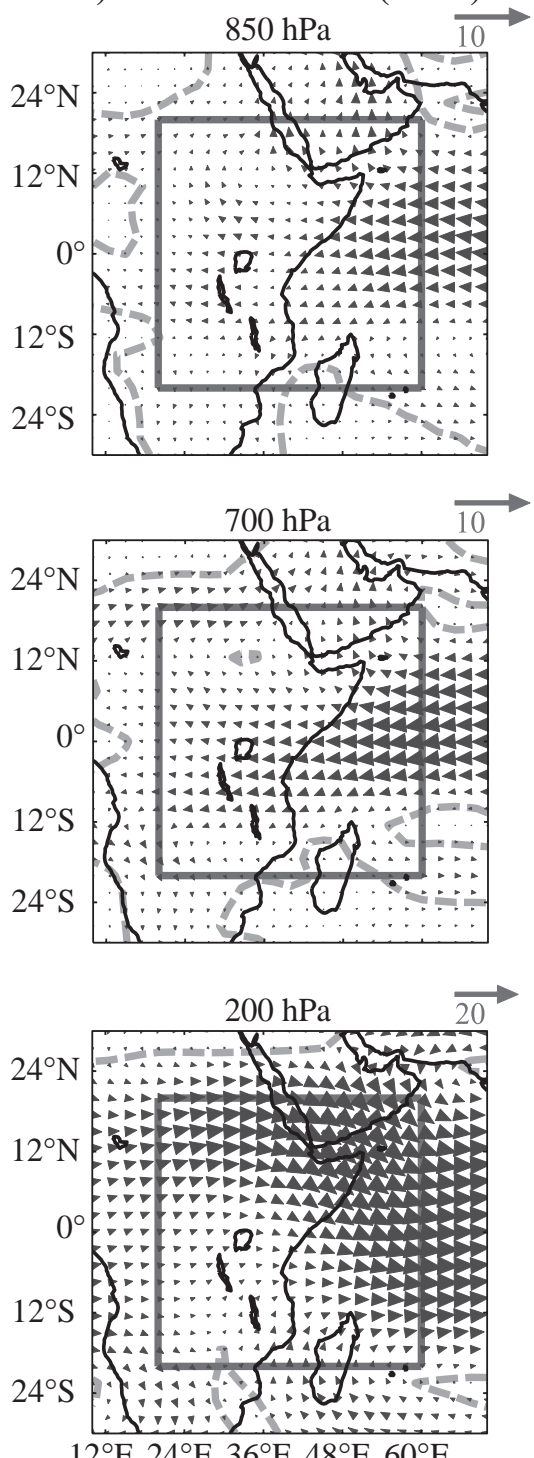

$12^{\circ} \mathrm{E} 24^{\circ} \mathrm{E} 36^{\circ} \mathrm{E} 48^{\circ} \mathrm{E} 60^{\circ} \mathrm{E}$ b) ANOVA between rainfall estimates

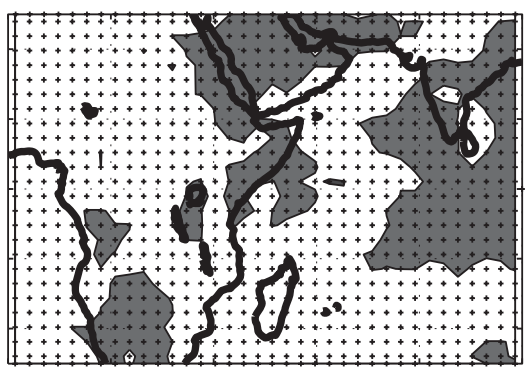

c) Geopotential height anomalies
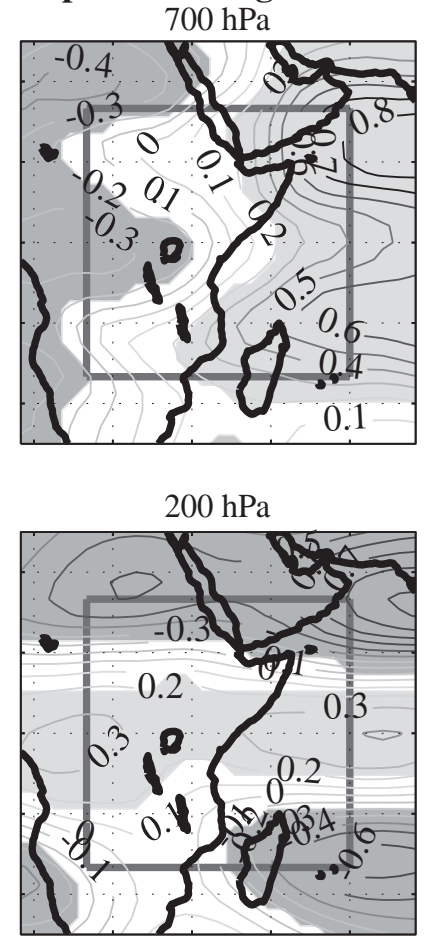

$12^{\circ} \mathrm{E} 24^{\circ} \mathrm{E} 36^{\circ} \mathrm{E} 48^{\circ} \mathrm{E} 60^{\circ} \mathrm{E}$

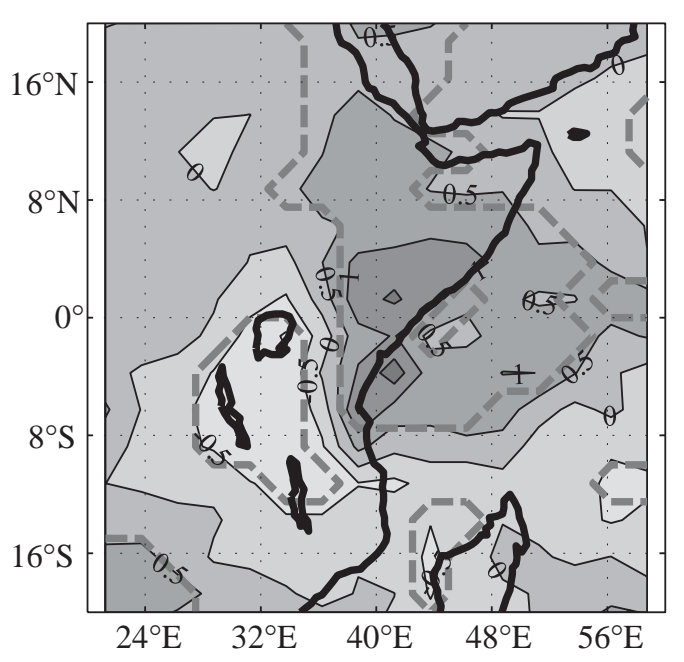

e) Seasonal distribution

Cluster 2

\section{d) GPCP-estimated rainfall anomalies}

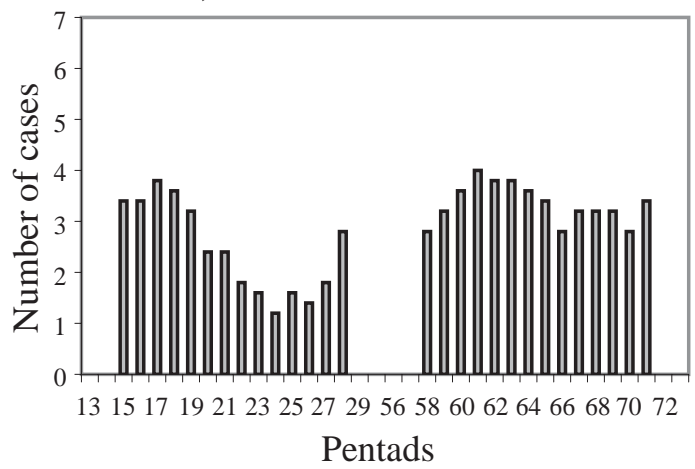

Fig. 4. Cluster 2, wind anomalies. All anomalies are calculated after removal of the annual cycle. See Fig. 3 for details

\subsection{Representation of classification results}

Figs. 3a to 9a present the circulation anomaly patterns, i.e. the deviations from the mean (the latter approximately shown in Fig. 1) averaged on all the pentads that constitute each cluster. The dashed lines on the circulation maps encompass significant anomalies according to the Hotelling $t^{2}$-test, at the $95 \%$ confidence level. The Hotelling test is the multivariate generalization of the $t$-test; in the present case it is applied to $U$ and $V$ (for details, see Sud et al. 1991, Von Storch \& Zwiers 1999). Intra-cluster homogeneity was empirically verified by extracting the 2 most dissimilar pentads of each cluster. The results seem quite robust and consistent for each of the obtained clusters, even if a large intra-cluster variance necessarily remains because of the small number of clusters. In order to further document the atmospheric configurations associated with each of the 7 clusters, the geopotential height standardized anomalies (not used in the cluster analysis) were also plotted (Figs. 3c to 9c) for the 2 levels 700 and $200 \mathrm{hPa}$. The $850 \mathrm{hPa}$ level is not shown because of its strong similarity with $700 \mathrm{hPa}$. The estimated-rainfall anomalies (GPCP dataset) associated with the clusters are also displayed (Figs. 3d to 9d); for each cluster an ANOVA was computed in order to 
a) Wind anomalies $\left(\mathrm{m} \mathrm{s}^{-1}\right)$

b) ANOVA between rainfall estimates
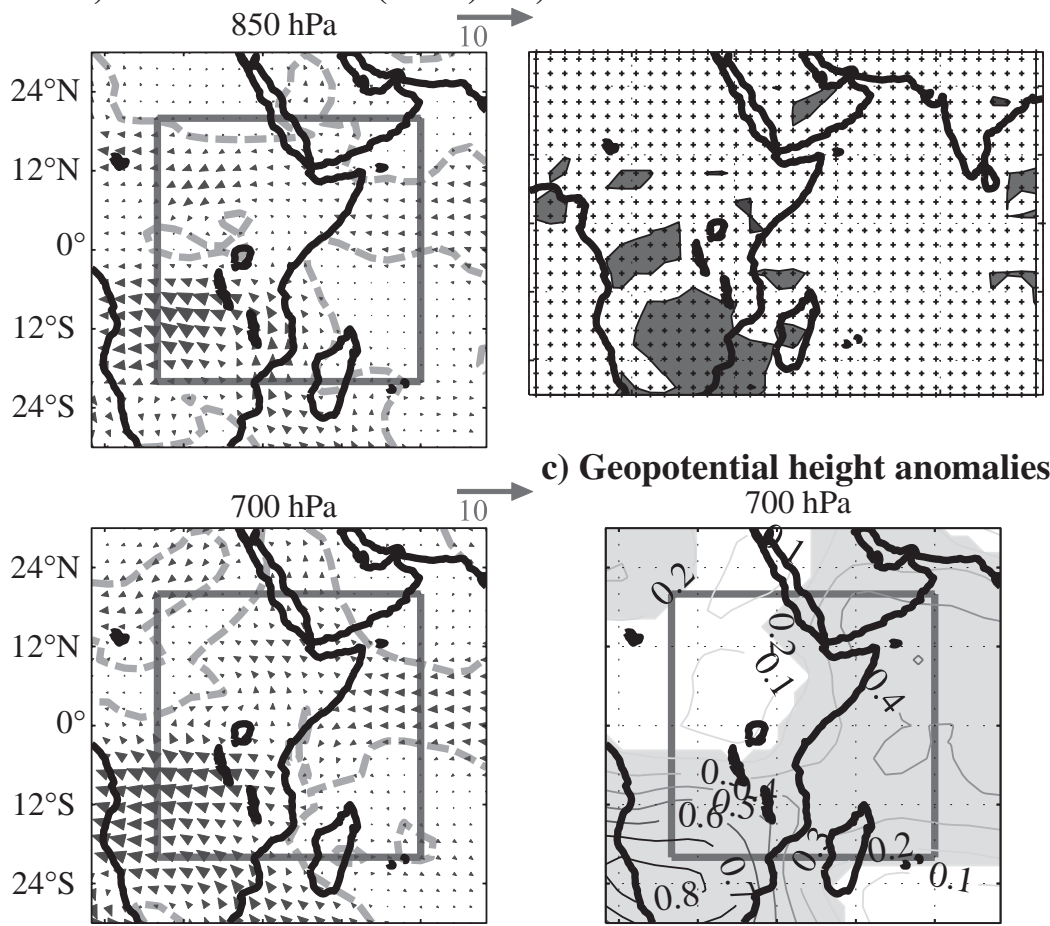

c) Geopotential height anomalies

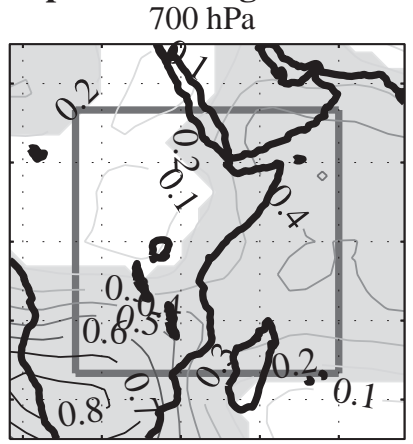

d) GPCP-estimated rainfall anomalies
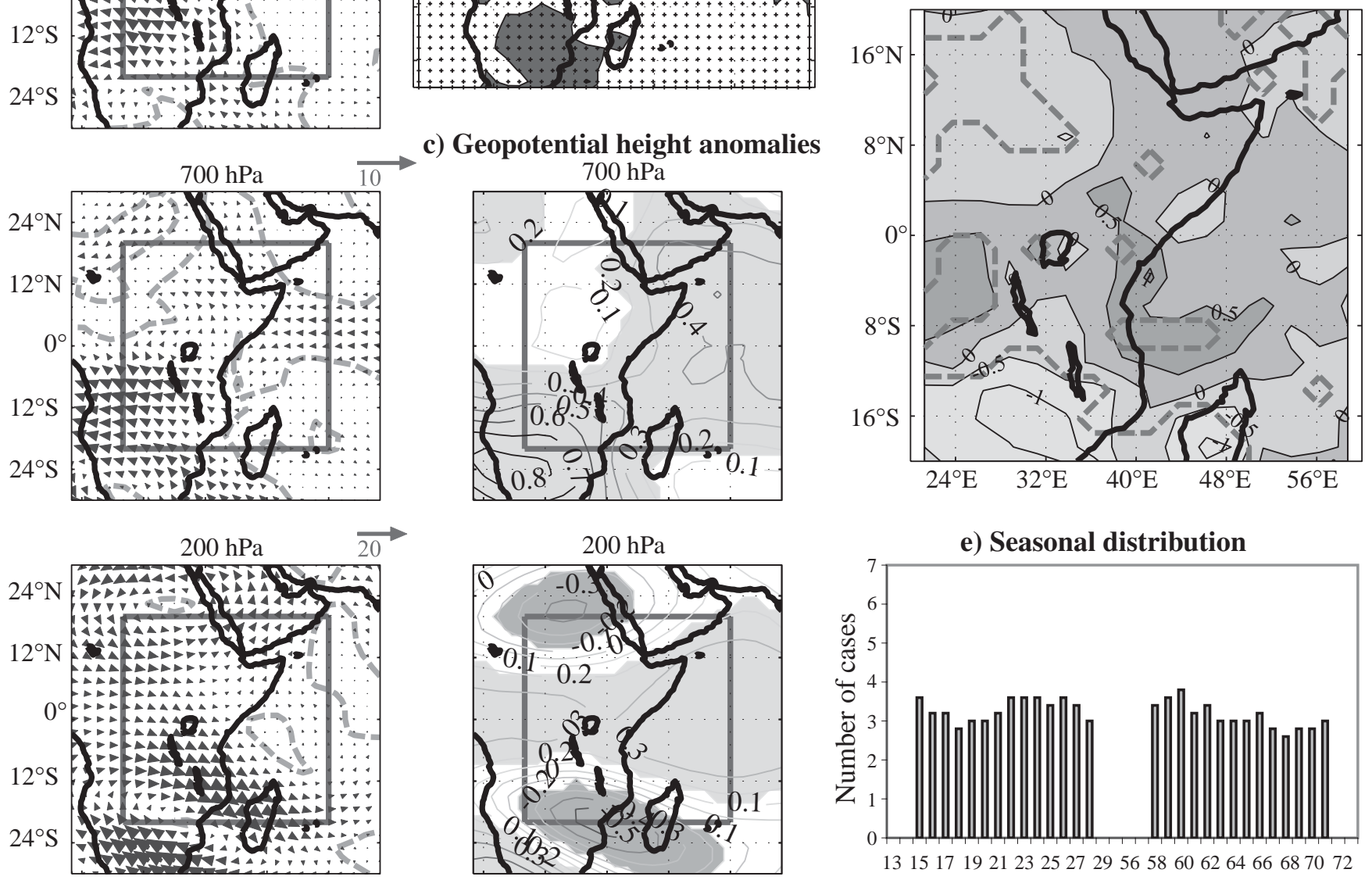

$12^{\circ} \mathrm{E} 24^{\circ} \mathrm{E} 36^{\circ} \mathrm{E} 48^{\circ} \mathrm{E} 60^{\circ} \mathrm{E}$

$12^{\circ} \mathrm{E} 24^{\circ} \mathrm{E} 36^{\circ} \mathrm{E} 48^{\circ} \mathrm{E} 60^{\circ} \mathrm{E}$

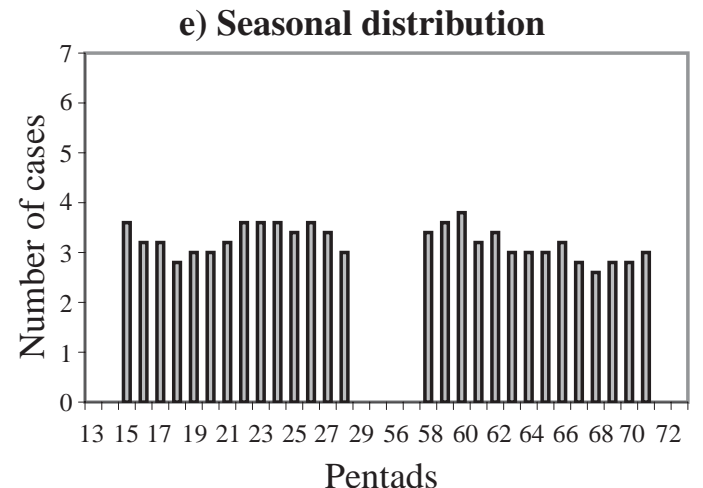

Fig. 5. Cluster 3, wind anomalies. All anomalies are calculated after removal of the annual cycle. See Fig. 3 for details

determine the regions where rainfall anomalies are significantly discriminated by their affiliation to the cluster (Figs. 3b to 9b). The frequency distribution of each cluster during the 2 seasons is also provided (Figs. 3e to 9e); for better readability, the results were filtered using a 3-pentad moving average.

Table 1 gives the size of each cluster; as noted in Huth (1996), the dynamical cluster analysis always tends to lead to approximately equal-size clusters. The temporal transitions between the different clusters were considered: for each occurrence of one cluster at one given pentad (referred to as Pentad $P^{1}$ ), the cluster to which the immediately-preceding pentad has been affected is recorded (Pentad $P^{0}$ ). The persistence of the anomaly patterns may be seen on the shaded diagonal (interpreted as $P^{0}$ and $P^{1}$ belong to the same cluster).
Table 1. Size of the clusters and transitions between the clusters: relative frequency $(\%), 1979-2002$

\begin{tabular}{|lrrrrrrrr|}
\hline \multirow{2}{*}{$\begin{array}{l}\text { Pentad } \\
P^{1}\end{array}$} & Size & \multicolumn{8}{c|}{ Pentad $P^{0}$} \\
\hline & & 1 & 2 & 3 & 4 & 5 & 6 & 7 \\
\hline 1 & 105 & 38.9 & 1.0 & 10.2 & 5.5 & 18.0 & 16.4 & 5.3 \\
2 & 106 & 2.0 & 40.6 & 8.3 & 17.2 & 6.3 & 2.1 & 6.2 \\
3 & 115 & 7.1 & 14.8 & 25.1 & 10.3 & 9.9 & 7.9 & 11.5 \\
4 & 151 & 12.2 & 17.8 & 14.8 & 34.6 & 15.3 & 13.6 & 15.0 \\
5 & 119 & 17.4 & 5.0 & 15.7 & 10.3 & 31.6 & 6.4 & 13.3 \\
6 & 146 & 16.3 & 4.0 & 14.8 & 9.7 & 12.6 & 34.3 & 21.2 \\
7 & 122 & 6.1 & 16.8 & 11.1 & 12.4 & 6.3 & 19.3 & 27.5 \\
Total & 864 & 100 & 100 & 100 & 100 & 100 & 100 & 100 \\
\hline
\end{tabular}


a) Wind anomalies ( $\mathrm{m} \mathrm{s}^{-1}$ ) b) ANOVA between rainfall estimates
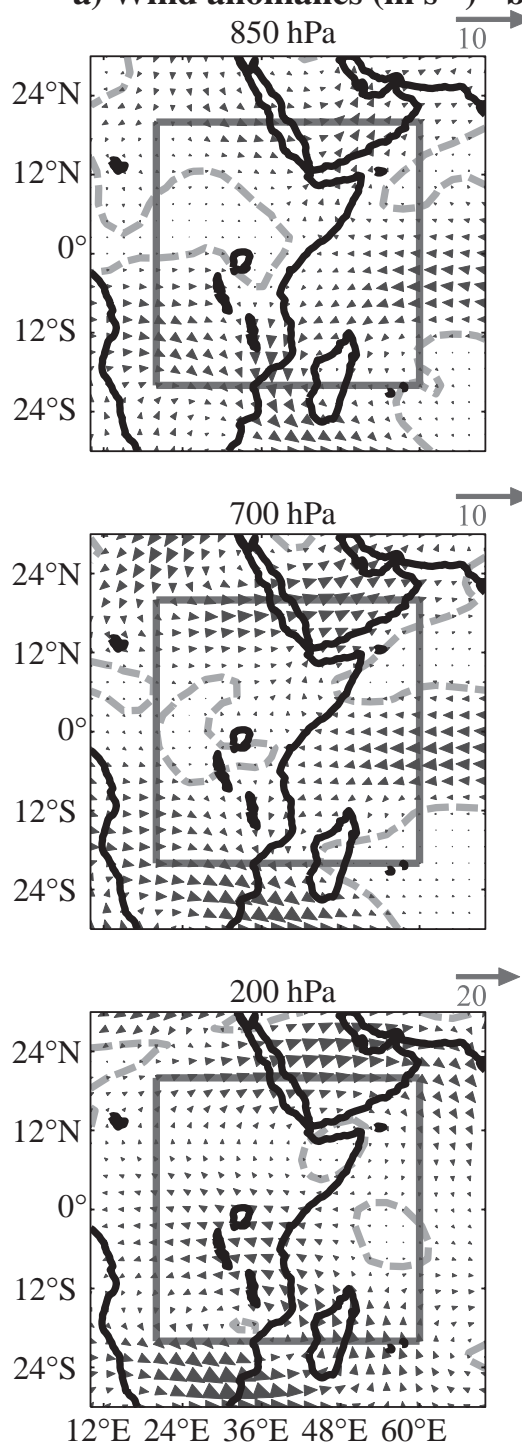

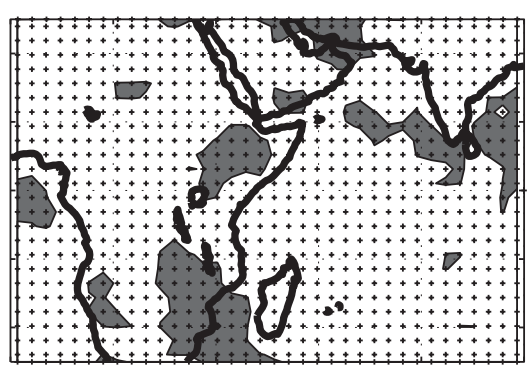

c) Geopotential height anomalies
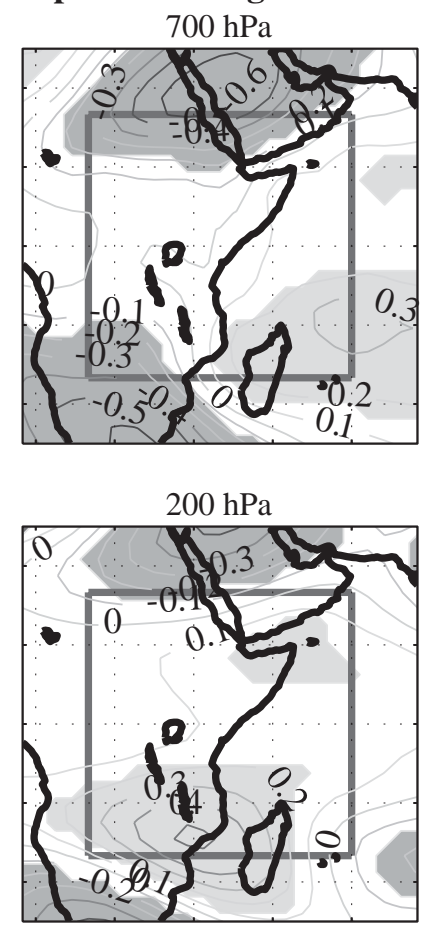

$12^{\circ} \mathrm{E} 24^{\circ} \mathrm{E} 36^{\circ} \mathrm{E} 48^{\circ} \mathrm{E} 60^{\circ} \mathrm{E}$ d) GPCP-estimated rainfall anomalies

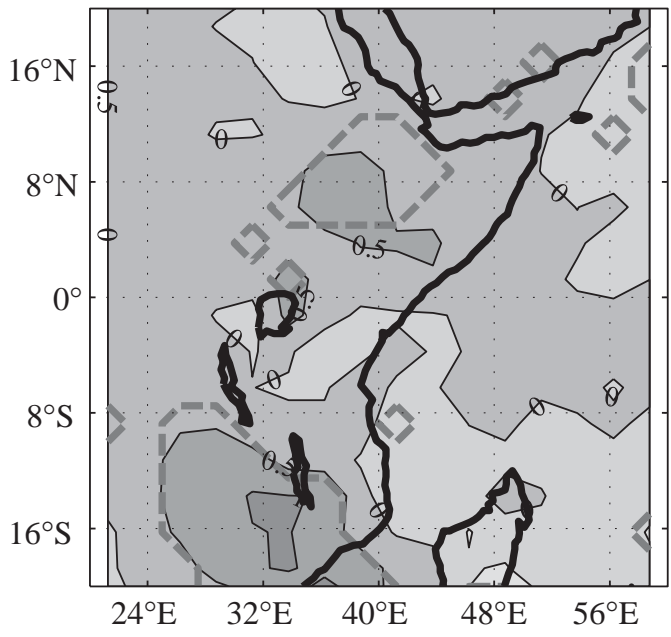

e) Seasonal distribution

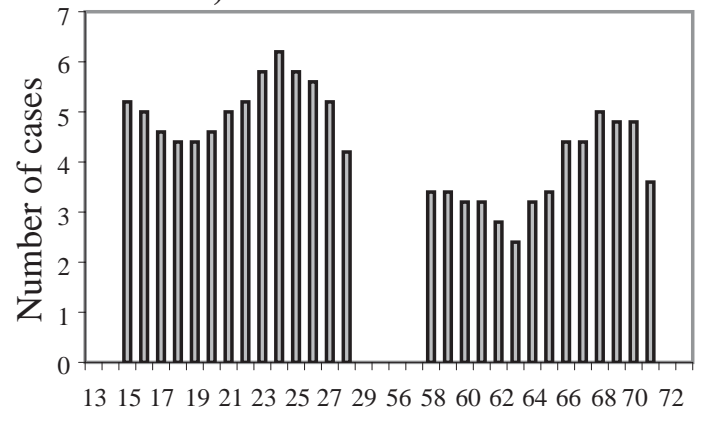

Pentads

Fig. 6. Cluster 4, wind anomalies. All anomalies are calculated after removal of the annual cycle. See Fig. 3 for details

\subsection{Interpretation of the clusters}

The different clusters are well separated from each other: for all clusters and levels taken together, $78.61 \%$ of the grid points display significant circulation anomalies ( $t^{2}$-test, 95\%). The significance increases in upper layers $(87 \%$ at $200 \mathrm{hPa}, 76 \%$ at $850 \mathrm{~Pa}$ and $73 \%$ at $700 \mathrm{hPa}$ ), but it also varies from one cluster to another (68\% for Cluster 3 vs $84 \%$ for Cluster 4). The efficiency of the dynamical cluster analysis is demonstrated, in agreement with Huth (1996), who compared different automatic classification processes.

Two clusters (1 and 2) display almost symmetrical patterns, as shown by the circulation anomaly maps
(Figs. 3a \& 4a) and the associated geopotential standardized anomalies (Figs. 3c \& 4c). These 2 clusters exhibit zonal wind anomalies over the Indian Ocean of opposite signs between the lower and midlevels, on the one hand, and the upper levels, on the other hand. For instance, Cluster 1 displays low- to midtropospheric westerly anomalies, and uppertropospheric easterly anomalies, both centred on the equatorial Indian Ocean. Abnormally low (high) geopotential heights are found at 700 (200) hPa over the NW and SW Indian Ocean. Such patterns are reminiscent of those associated with equatorial zonal circulation cells, suggesting subsiding/ascending motions between higher and lower levels (confirming the principle of conservation of atmospheric mass). 
a) Wind anomalies $\left(\mathrm{m} \mathrm{s}^{-1}\right)$ b) ANOVA between rainfall estimates

Cluster 5
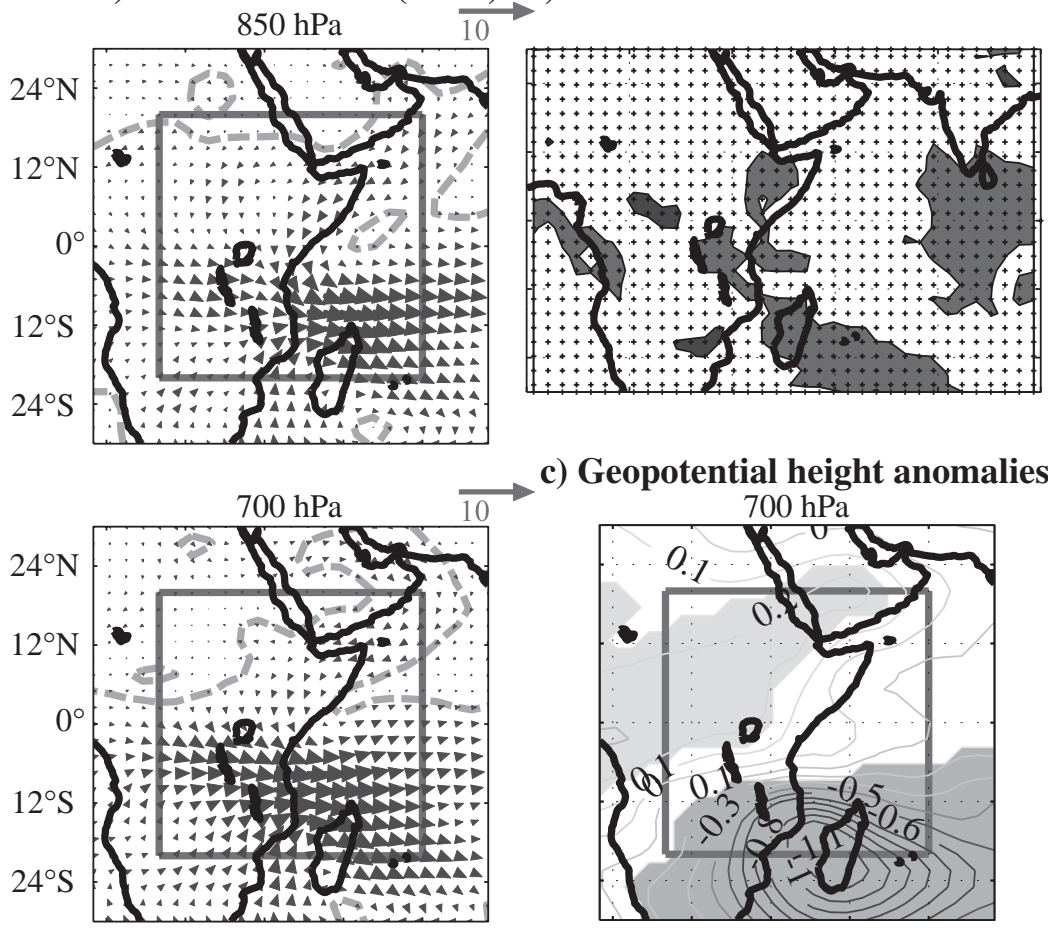

c) Geopotential height anomalies

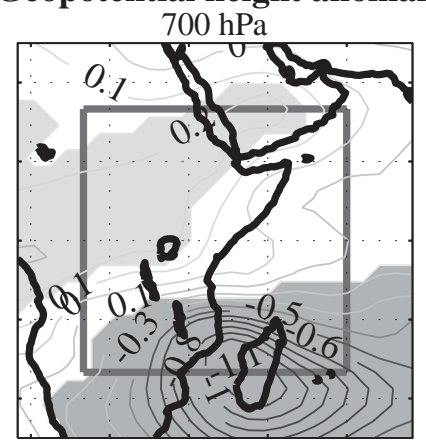

d) GPCP-estimated rainfall anomalies
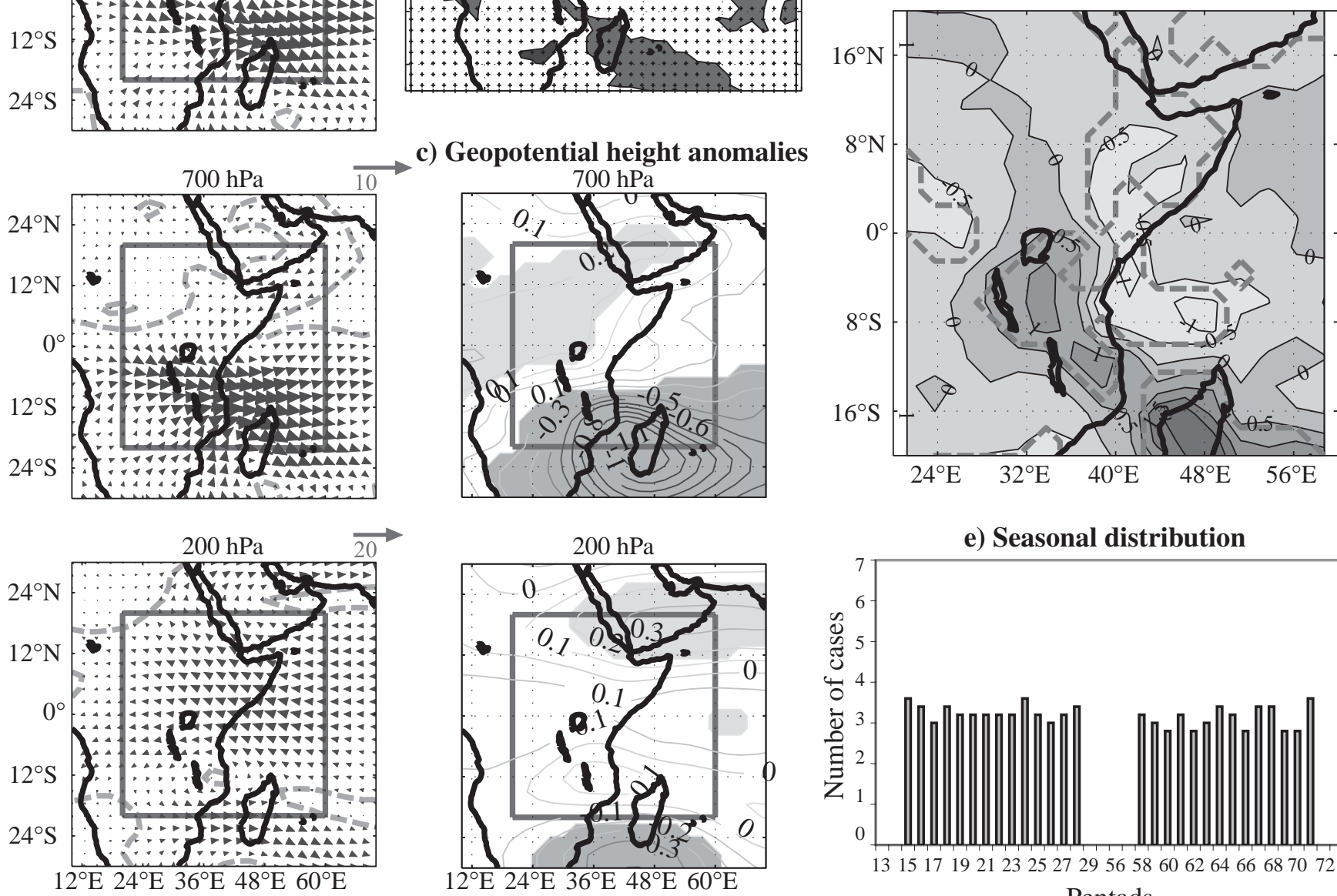

e) Seasonal distribution

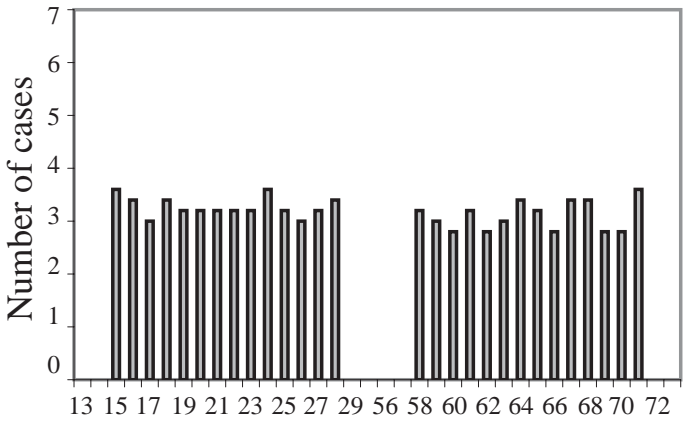

Pentads

Fig. 7. Cluster 5, wind anomalies. All anomalies are calculated after removal of the annual cycle. See Fig. 3 for details

In order to ascertain the presence of ascending or subsiding anomalies and the role of East-African topography, Fig. 10 presents vertical sections of the atmosphere along the equator, depicting the mean situation and the anomalies associated with these 2 clusters. Fig. 10a shows the mid- to uppertropospheric subsidence observed on average over EEA. The surface topography is also seen to strongly impact the lowerlevel circulation, by forcing the ascent of the low-level easterlies on the eastern slopes. Considering the 2 clusters (Fig. 10b,c), the anomaly patterns appear once again almost perfectly symmetrical. Over the EastAfrican Highlands the vertical motion appears symmetric with the flows observed over the Congo Basin, thus forming a consistent African cell apparently well identified and adjoining the large-scale circulation patterns located over the equatorial Indian Ocean. Even if the local dynamics and/or the topography complicate the atmospheric configurations, Cluster 1 (Cluster 2) seems to characterize an atmospheric cell exhibiting a downward (upward) motion over the EastAfrican and west-Indian Ocean longitudes.

The rainfall fields over the Indian Ocean are spatially coherent (Figs. 3d \& 4d) and consistent with the observed large-scale vertical motion anomalies (Fig. 10). In contrast, the precipitation response over the EEA region appears spatially more contrasted, probably due to the local topography.

Cluster 1 exhibits significant positive rainfall anomalies over the East-African Highlands (Fig. 3d), which 

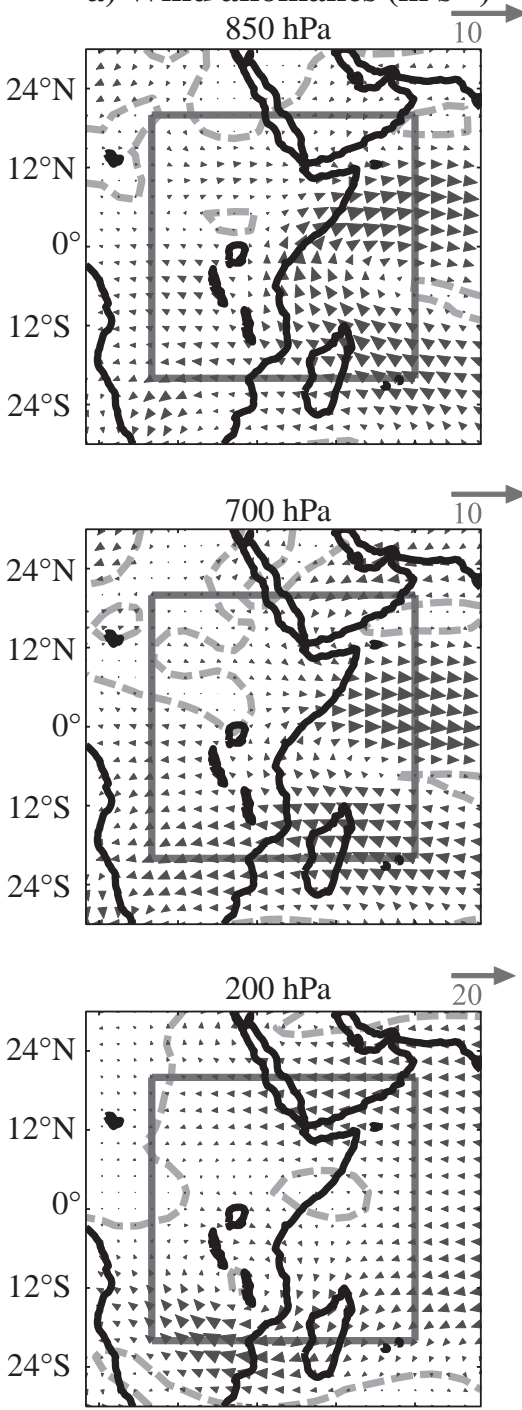

$12^{\circ} \mathrm{E} 24^{\circ} \mathrm{E} 36^{\circ} \mathrm{E} 48^{\circ} \mathrm{E} 60^{\circ} \mathrm{E}$

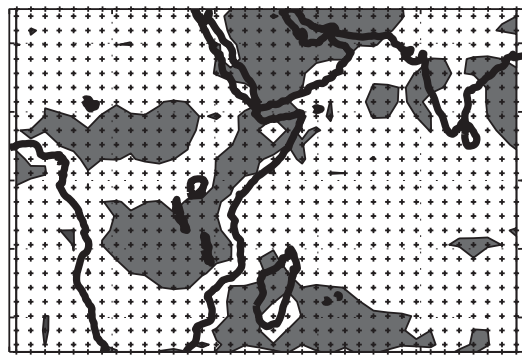

c) Geopotential height anomalies
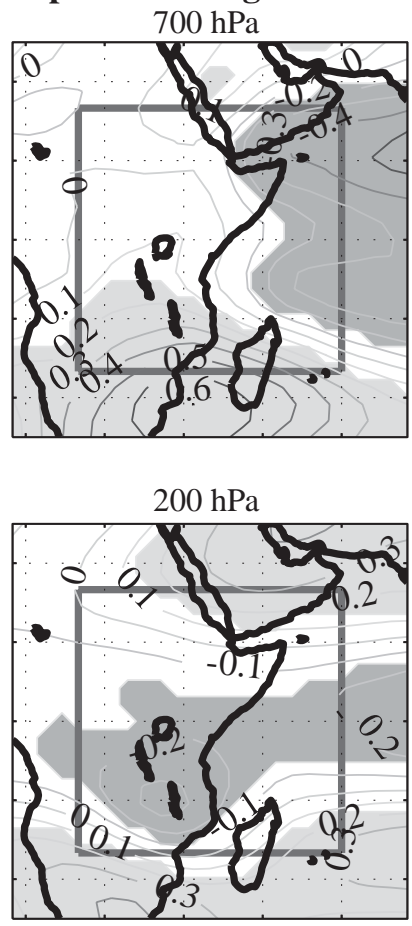

$12^{\circ} \mathrm{E} 24^{\circ} \mathrm{E} 36^{\circ} \mathrm{E} 48^{\circ} \mathrm{E} 60^{\circ} \mathrm{E}$
Cluster 6

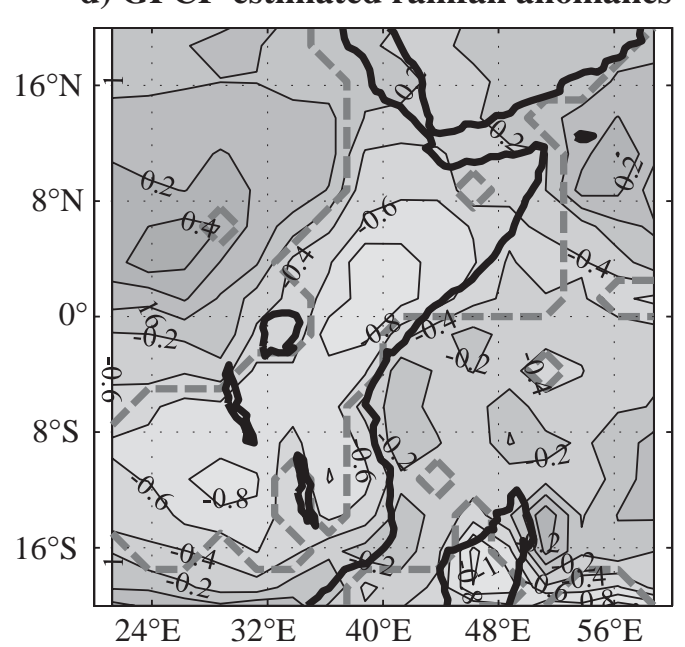

e) Seasonal distribution

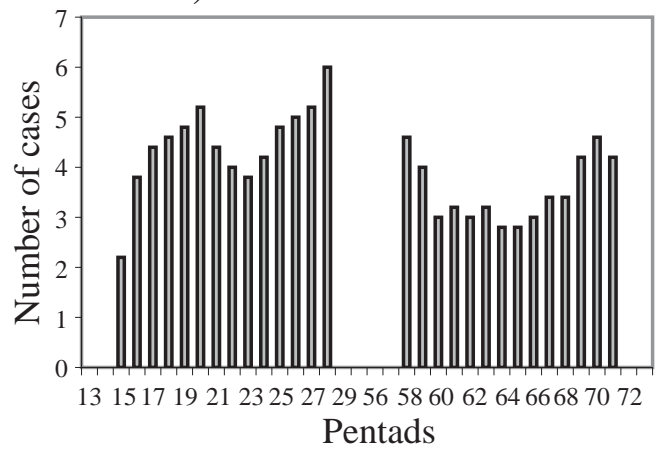

Fig. 8. Cluster 6, wind anomalies. All anomalies are calculated after removal of the annual cycle. See Fig. 3 for details

is consistent with the ascending motion observed in the troposphere, whereas coastal plains experience weak negative rainfall anomalies. Rainfall amounts thus appear to be closely related to the vertical atmospheric circulation. Cluster 2 (Fig. 4d) clearly exhibits a symmetrical zonal dipole centred on the EEA region that is also consistent with the vertical circulation anomalies (Fig. 10c). Clusters 1 and 2 also discriminate the precipitation amounts over the major parts of the Indian Ocean Basin (Figs. 3b \& 4b).

Zonal circulation anomalies over Equatorial Africa present contrasted impacts on EEA rainfall, whereby the coastal region wet/dry spells seem to be out-ofphase with those of the Highlands. These results are consistent with Pohl \& Camberlin (unpubl.). In addition, the circulation maps associated with Clusters 1 and 2 (Figs. 3a \& 4a) resemble the circulation patterns associated at the intraseasonal timescales with the MJO (Madden \& Julian 1994, Wheeler \& Hendon 2004). The relationships between the 2 clusters and the MJO will therefore be examined in detail in Section 4.4.

Clusters 1 and 2 present the strongest persistence (Table 1) and these 2 opposite configurations in practise never succeed each other. Their seasonal distribution is relatively similar, peaking (especially for Cluster 1) in October and early November.

Cluster 3 (Fig. 5) exhibits weak circulation anomalies at 850 and $700 \mathrm{hPa}$. A reinforcement of the southern trade winds over Zambia and the southern Congo Basin is perceptible. In return, a pair of cyclonic anom- 
a) Wind anomalies $\left(\mathrm{m} \mathrm{s}^{-1}\right)$ b) ANOVA between rainfall estimates

Cluster 7
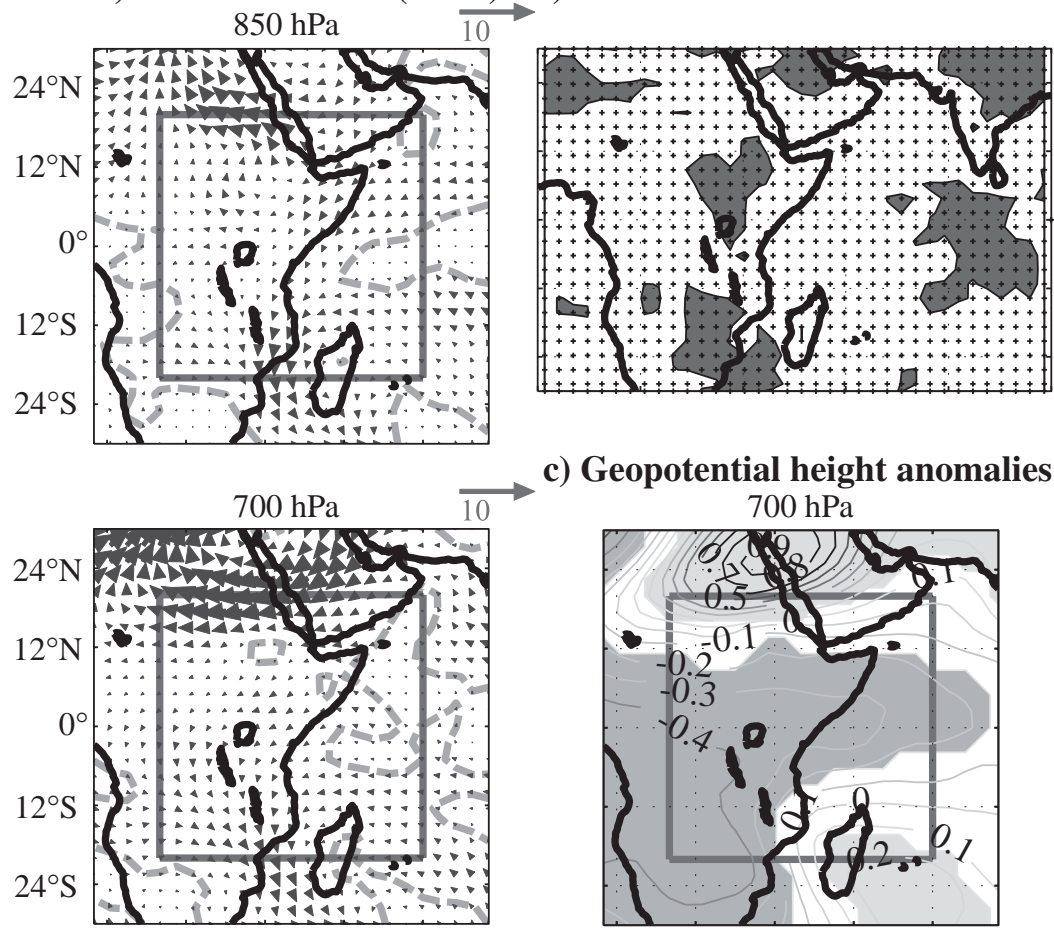

c) Geopotential height anomalies

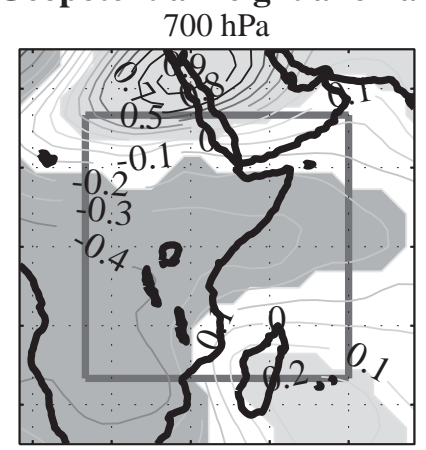

d) GPCP-estimated rainfall anomalies
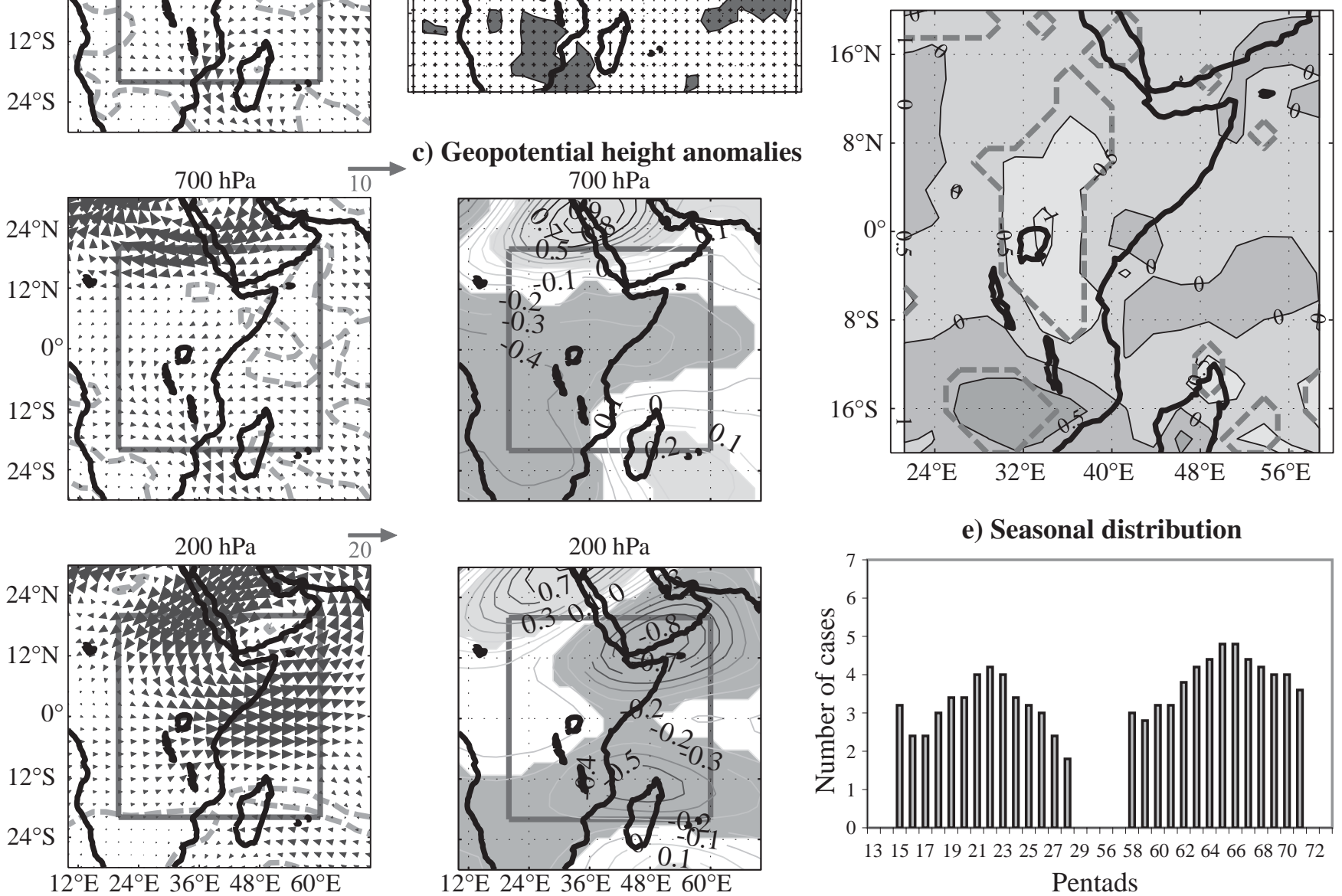

e) Seasonal distribution

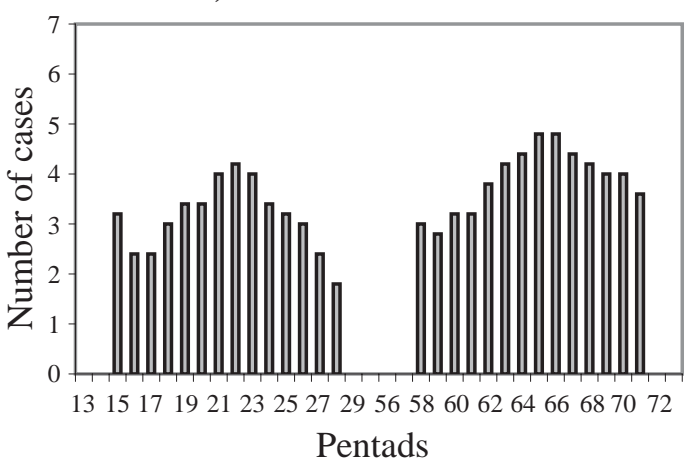

Fig. 9. Cluster 7, wind anomalies. All anomalies are calculated after removal of the annual cycle. See Fig. 3 for details

alies corresponding to negative geopotential anomalies appears in upper layers in each hemisphere, approximately at $25^{\circ}$ latitude on the $30^{\circ} \mathrm{E}$ meridian. This pattern has already been empirically observed by Johnson \& Mörth (1960), and it corresponds in their simplified classification of the most common circulation patterns to the 'bridge' model, i.e. a pair of troughs on each side of the Equator and quasi-geostrophic winds in each meteorological hemisphere. Their theoretical model is, however, not restricted to the upper layers. Associated rainfall anomalies (Fig. 5d) are weak over EEA. Enhanced rainfall is found over the Congo Basin, whereas dry conditions prevail over southern Africa and Madagascar. Both are significantly discriminated by the cluster (Fig. 5b). In contrast to the first 2 clusters, Cluster 3 presents the lowest persistence
(Table 1), and its temporal distribution is quite uniform through the seasonal cycle.

The Cluster 4 pattern (Fig. 6) consists of a lowerlayer, east-to-west juxtaposition of a cyclonic cell and an anticyclonic cell in the southern hemisphere, separated from each other by northwesterly anomalies extending from the Great Lakes to Madagascar. In the upper layers an anticyclonic cell centred over Mozambique and a cyclonic cell over the Arabian Peninsula face each other on each side of the Equator. This configuration is close, in the upper layers, to the 'crossequatorial drift' described by Johnson \& Mörth (1960) as the opposition of a high-pressure cell and a lowpressure cell in each hemisphere, generating a transequatorial flow. However, the drift model more particularly refers to lower-level circulation patterns, and it 

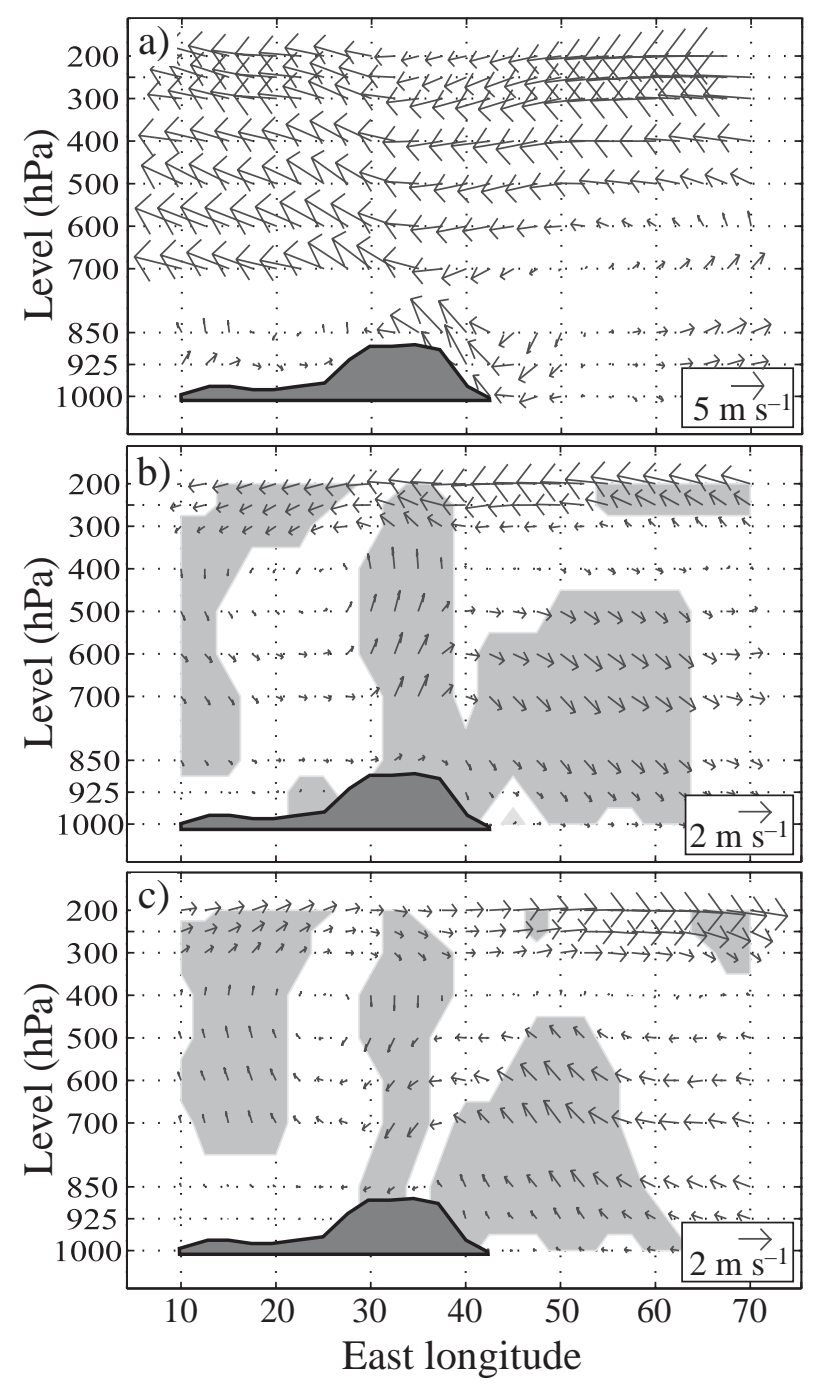

Fig. 10. Atmospheric cross-sections of the zonal and vertical components of the wind at the equator. The topography is represented such as it appears in the NCEP-NCAR spectral model. (a) Mean circulation. (b) Circulation anomalies associated with Cluster 1 ; shaded areas show significant anomalies according to the Hotelling test applied to the zonal $(U)$ and vertical $(\omega)$ components of the wind at the $95 \%$ confidence limit. (c) Same as (b) but for Cluster 2

is a characteristic feature of the summer monsoon, which is not the topic of the present study. Associated rainfall anomalies concern mainly southern Africa and secondarily Ethiopia (both abnormally wet; Fig. 6d). The cluster appears able to significantly discriminate these rainfall anomalies. These results are consistent with Todd \& Washington (1999), who identified northwesterly anomalies running from the Congo Basin to Madagascar as a recurrent pattern associated with abnormally wet spells over southern Africa. Cluster 4 is also characterized by a strong persistence (Table 1) and by a higher number of cases in MAM.
Cluster 5 (Fig. 7) essentially exhibits a strong lower-layer westerly signal in the low southern latitudes, corresponding to a weakening of the southern hemisphere trade winds. It is related to the development of a deep trough over Madagascar. A moderate reinforcement of the northern trade winds, especially over the Horn of Africa, is also observed. Upper-layer anomalies are from the east or SE in a major part of the domain, concomitant with 2 anticyclonic anomaly cells centred on the south of Mozambique and on the SE of the Arabian Peninsula. Associated precipitation anomalies are positive on a SE-NW diagonal running from Madagascar to Lake Victoria, and are negative over the Horn of Africa, the Kenyan coast region and the western equatorial Indian Ocean. Such a pattern is recurrently associated with wet spells over southern Africa and Madagascar (Washington \& Todd 1999). It may also be in close interaction with the mid-latitude lows (Todd \& Washington 1999), which would be consistent with the negative geopotential height anomalies observed on the austral margin of the domain (Fig. 7c). Concerning rainfall anomalies, moisture advections from the Congo Basin air mass, in connection with the weakening of the southern trade winds, seem to largely explain the wet anomalies observed over SE Africa. Similarly, dry air advections may occur over the Horn of Africa from the Asiatic land mass, in relation to the moderate strengthening of the diffluent northern trades. On both the African landmass and Madagascar the areas experiencing wet conditions correspond to regions with marked topography, and orographic ascents are likely to be involved in the condensation of lowerlevel moisture. The circulation anomalies at the 3 levels, the associated rainfall anomalies and the transitions between the clusters (Table 1) reveal similarities with Cluster 1 . The 2 clusters preferentially succeed each other. However, they present a dissimilar seasonal distribution, Cluster 5 being uniformly recorded across the 2 seasons.

Clusters 6 and 7 are related to each other, as shown by their preferred temporal transition (Table 1), and their out-of-phase distribution through the seasonal cycle (Figs. 8d \& 9d). In lower and mid-layers, circulation anomalies associated with Cluster 6 (Fig. 8a) are reminiscent of the boreal summer monsoon flow established over the region during July-September. The seasonal distribution is consistent with this point, more cases occurring just before and just after the boreal summer. At these times of the year, this cluster corresponds to enhanced monsoon circulation. The signal, in fact, displays a weakening of the northern trades and a strengthening of the southern trades, and thus appears as quite symmetrical to the patterns associated with Cluster 5. In upper layers easterly anomalies pre- 
vail in the north and the south, and a cyclonic pattern located over Lake Malawi reinforces these anomalies on their southern rim, near southern Mozambique. Associated rainfall anomalies (Fig. 8d) are significantly negative over a large area, especially on a SW-NE diagonal extending from southern Africa to Arabia via EEA. Divergence anomalies observed over the eastern part of the continent, as well as a possible role for the East African topography as a barrier, may be involved in explaining these patterns. A separate analysis of the 2 rainy seasons reveals quite dissimilar structures, the dry areas affecting only the northern part of the diagonal in MAM and only its southern part in OND. The lower hygrometric capacity of the air masses, generated by the lower temperatures after the southern hemisphere winter season, may largely contribute to causing these differences.

Cluster 7 (Fig. 9) is essentially dominated by an upper-tropospheric signal consisting of an anticyclonic flow (positive geopotential anomalies) over Egypt and a cyclonic flow (negative geopotential anomalies) over southern Arabia. Some lower-layer divergence is also observed around EEA. Associated rainfall anomalies are negative and significant over the Highland region, as a possible result of upper-layer confluence and lower-layer diffluence. The positive rainfall anomalies in the Kalahari Desert region may be related to the lower-layer northwesterly anomalies, seen to cause above-normal precipitations in the southern part of Africa by advecting moisture from the Congo Basin (Todd \& Washington 1999).

\subsection{Intraseasonal and interannual modulations of the clusters}

Even though the clusters are approximately equally sized (Table 1), leading to similar frequencies of appearance over the overall period, the cluster occurrences exhibit substantial intraseasonal and interannual variabilities. Their possible association with the dominant modes of climate variability at these time scales thus deserves to be explored.

At the intraseasonal timescale, the dominant mode of atmospheric variability within the tropical belt is characterized by an eastward migration of zonal cells along the Equator. It is mainly found over the Indian and the western Pacific basins (Madden \& Julian 1971, 1972, 1994). Consequently, convective cloud clusters (cloudfree areas) also migrate eastward, their location approximately corresponding with ascending (subsiding) motion. This phenomenon appears as a pseudo-cycle with a period varying from 30 to $60 \mathrm{~d}$, known as the Madden-Julian Oscillation (MJO). The signal is very consistent spatially and significant anomalies are found in zonal wind (at both upper and lower levels), OLR and sea-level pressure.

The modulation of the frequency of the different clusters by the MJO is evaluated using the indices developed by Wheeler \& Hendon (2004). The intraseasonal cycle is decomposed into phase $(\alpha$, varying from 0 to $2 \pi$ radians) and amplitude measurements, which offers the advantage of suppressing the nonstationarity of the period ( 30 to $60 \mathrm{~d}$ ). The present study makes use of the phase values in order to locate the main MJO-related convective cells along the equator. For example, for $\alpha=\pi$, enhanced convection is observed over western Africa; for $\alpha=3 \pi / 2$ it takes place over the eastern Indian Ocean; and at $2 \pi$, it has reached the Maritime Continent/Western Pacific.

Fig. 11 presents the frequency of the 7 clusters as a function of the MJO phase. The circulation anomaly patterns describe recurrent configurations that are preferentially observed at given phases of the intraseasonal cycle. Almost $40 \%$ of the occurrences of Cluster 1 are observed during the MJO phase $3 \pi / 2$, during which easterly (westerly) anomalies are observed over the Indian Ocean in the lower (upper) layers of the tro-

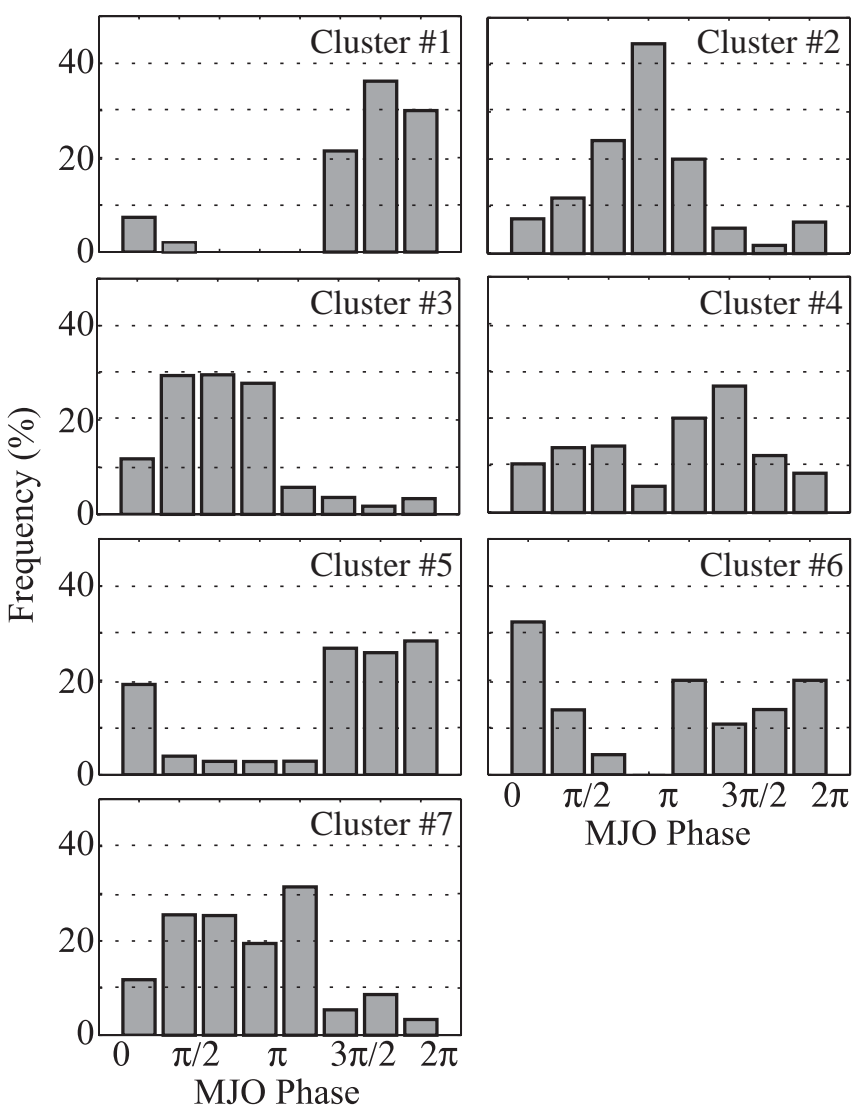

Fig. 11. Frequency of occurrences of the clusters over the intraseasonal oscillation, expressed as a percentage of the total number of pentads for each cluster 
posphere (Wheeler \& Hendon 2004). Enhanced convection is located at this phase over Indian longitudes, and positive rainfall anomalies are then found over the eastern Indian Ocean. Fig. 3b actually shows precipitation significantly discriminated over this area (Fig. 3b). The cluster is never observed during the opposite phase of the MJO (from $\pi / 2$ to $\pi$ ). The similarities noted between Clusters 1 and 5 are also observed as far as their distribution over the MJO cycle is concerned. The positive rainfall anomalies observed over the Highlands during the occurrences of the cluster have to be interpreted as a delay of the East African convection, consistent with Pohl \& Camberlin (unpubl.). Such a hypothesis is reinforced by the vertical component of the wind pattern (Fig. 10b).

In contrast, Cluster 2 is most often found during the MJO phase $\pi$ (westerly lower-layer and easterly upperlayer anomalies over the Indian Ocean and convection over western Africa). More than $45 \%$ of its occurrences are recorded during this phase of the cycle. The eastern Indian Ocean then experiences dry conditions (not shown), also significantly discriminated by the cluster (Fig. 4b). Cluster 2, found to be symmetric with Cluster 1 , appears to characterize another phase of the MJO, which explains why the 2 patterns, in practice, never succeed each other (Table 1). Clusters 3 and 7 are also recurrently recorded at this phase of the MJO. The 2 remaining clusters (4 and 6) are distributed more homogeneously over the intraseasonal cycle. The obtained partitioning is then strongly constrained by the circulation anomalies induced or at least in relationship with the MJO over the Eastern Africa-Western Indian Ocean region.

At the interannual timescale, the dominant mode of atmospheric and oceanic variability in the Indian Ocean Basin is the El Niño-Southern Oscillation (ENSO). The Southern Oscillation Index (SOI) was used as an indicator for this phenomenon. The Dipole Mode Index (DMI; Saji et al. 1999) was also used as an indicator of the zonal SST gradient in the equatorial Indian Ocean. Correlations between the number of occurrences of each cluster and these indices were applied to evaluate the effects of the El Niño/Dipole Mode Event years on the intraseasonal variability of the atmospheric patterns (Table 2).

For the OND season, the interannual fluctuations in the number of occurrences of the different clusters were not related to these dominant modes of variability. For the MAM season the DMI interannual fluctuations do not significantly affect the number of occurrences of the clusters, but the results with the SOI exhibit significant results. Clusters 2 and 5 occur more frequently during El Niño events, while Clusters 1 and 6 are more often recorded during La Niña years. Easterly anomalies seem to be more often recorded over
Table 2. Correlations between the the Southern Oscillation Index (SOI)/Dipole Mode Index (DMI) and the number of occurrences of the clusters for MAM and OND. Significant correlations (Bravais-Pearson test, 95\% confidence limit) marked in bold

\begin{tabular}{|rrrrr|}
\hline & \multicolumn{2}{c}{ MAM } & \multicolumn{2}{c|}{ OND } \\
& DMI & SOI & DMI & SOI \\
\hline 1 & -0.05 & $\mathbf{0 . 4 4}$ & -0.25 & 0.06 \\
2 & -0.21 & $\mathbf{- 0 . 5 8}$ & 0.26 & -0.39 \\
3 & 0.12 & -0.30 & 0.30 & -0.23 \\
4 & -0.08 & -0.23 & 0.44 & -0.26 \\
5 & $\mathbf{0 . 6 2}$ & $\mathbf{- 0 . 5 8}$ & 0.08 & -0.29 \\
6 & -0.23 & $\mathbf{0 . 6 5}$ & -0.39 & $\mathbf{0 . 6 0}$ \\
7 & -0.08 & 0.33 & -0.41 & $\mathbf{0 . 4 3}$ \\
\hline
\end{tabular}

the equatorial Indian Ocean during the northern springs following immediately after a La Niña event, which is consistent with the negative (positive) SST anomalies off the Kenyan (Indonesian) coast usually associated with this phase of ENSO. However, the interpretation of the results remains ambiguous, because the 2 pairs of clusters only present limited similarities in terms of wind and rainfall anomaly patterns. Moreover, the statistical independence found for the OND season remains startling.

\subsection{Rainfall anomaly discrimination}

The typology of the circulation anomaly patterns obtained by dynamical cluster analysis seems quite suitable for discriminating both rainfall anomalies and atmospheric configurations, as some of the results resemble previously known patterns. In order to confirm the ability of the classification to discriminate wet and dry events at the intraseasonal timescale, the variance of the pentad rainfall anomalies explained by the clusters was compared with the residual (intra-cluster) variance. Fig. 12 shows the results of an ANOVA applied on rainfall at each grid point of the GPCP grid, to test the ratio between within-cluster variance and centroid-variance. All the 864 pentads included in MAM + OND 1979-2002 are considered.

Over a major part of the African continent (especially EEA and southern Africa), rainfall amounts are significantly discriminated by the clusters. However, the precipitation in the Sahara Desert (where rainfall amounts are low) and the eastern Congo Basin are poorly discriminated by the 7 clusters. For the latter, better results might have been obtained by extending the domain westwards, to encompass the West African monsoon area.

A clear distinction between the African land mass and the western Indian Ocean also appears. The non- 


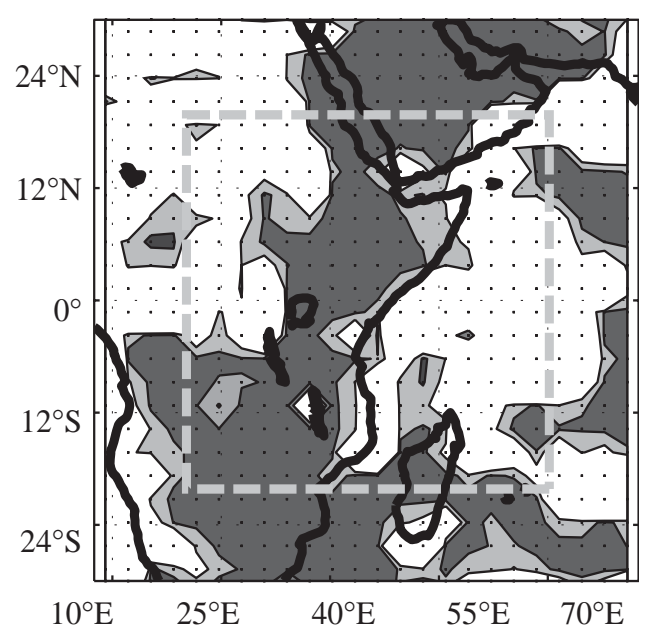

Fig. 12. ANOVA between the classification and GPCPestimated precipitations. Shaded areas delimit significantly discriminated pentad rainfall anomalies (light grey: $95 \%$ confidence level, dark grey: 99\% confidence level) in MAM + OND 1979-2002. The classification domain is shown as a box

significant results obtained for the latter area could result from either the fact that intra-seasonal variability of rainfall amounts bears little relationship with local wind anomalies or the fact that the GPCP data over the Indian Ocean are not fully reliable (since rainfall estimates over the ocean are derived from satellite data such as microwave SSM/I, or OLR). However, over the whole domain, $57.7 \%$ of the GPCP grid points are significantly discriminated by the partition at the $95 \%$ confidence limit, and $42.6 \%$ at the $99 \%$ confidence limit. This demonstrates the validity and usefulness of the partition, though it should be noted that it is not necessarily the best tool for differentiating rainfall patterns over the region.

\section{CONCLUSIONS}

A dynamical cluster analysis was applied to the NCEP-2 zonal $(U)$ and meridional $(V)$ circulation anomaly fields, averaged on a pentad (5 d) timescale, for a domain extending from $20^{\circ} \mathrm{N}$ to $20^{\circ} \mathrm{S}$ and 20 to $60^{\circ} \mathrm{E}$, centred on equatorial East Africa. For the East African MAM and OND rainy seasons in 1979-2002, the analysis led to a partition into 7 clusters.

The partition significantly discriminates wind anomalies over a major part of the domain (Hotelling test, $95 \%$ confidence level) but also precipitation anomalies, essentially on the eastern and SE parts of the African continent (ANOVA, 95\% confidence limit). Four of the 7 clusters obtained are involved in particularly wet or dry spells over eastern Africa.
On the one hand, some of the clusters correspond more or less to previously known patterns such as the 'bridge' and the 'drift' models, empirically described by Johnson \& Mörth (1960). Others strongly resemble the patterns associated with abnormally wet spells over southern Africa and Madagascar, interacting with the mid-latitude lows (Todd \& Washington 1999). Of interest here is that an objective and systematic partitioning has pointed out atmospheric configurations that had been recurrently observed by synoptical meteorologists, or identified by previous studies. On the other hand, 2 clusters clearly resemble the cellular patterns that are usually associated with opposite phases of the Madden-Julian Oscillation; their phase-locking to the intraseasonal cycle reinforces this conclusion. The rainfall anomalies associated with these clusters suggest that the East African relief complicates the local response of the rains to these circulation patterns. More generally, 5 of the 7 clusters are closely related to given phases of the Madden-Julian Oscillation, confirming that it is the dominant mode of variability at the intraseasonal timescale over the region. The El Niño-Southern Oscillation also partly controls the frequency of the clusters during the northern spring season.

Nevertheless, partition remains a simplifying approach to the variability of atmospheric configurations. Of course, it objectively describes the most frequent patterns, but it does not pretend to capture or to accurately approximate their whole spatial and temporal diversity. Atmospheric fields such as geopotential height or wind flows are indeed continuous functions of time, and such a classification artificially makes analysed variables discrete. However, partitioning algorithms, such as dynamical cluster analysis, have already shown their utility in climatology and meteorology in several studies. The fundamental aim of such approaches is to explain a maximum of variance (by describing as accurately as possible the atmospheric fields) with a minimum number of clusters.

The physical nature of the rain-causing processes is still to be explored. Beyond the influence of the Madden-Julian Oscillation on East African rainfall (B. Pohl \& P. Camberlin unpubl.), the obtained patterns suggest a probable contribution of the mid-latitude disturbances on regional circulation and precipitation anomalies. The latter aspect may constitute the object of forthcoming studies.

Acknowledgements. The authors thank the 'Climate Variability Analysis Group' (CNRS INLN, Nice, and CNRS LMD, Paris), who computed the red-noise tests in the ANAXV software package. This work was carried out as a part of the LOTI project funded by the French Programme National d'Etudes de la Dynamique du Climat (PNEDC). 


\section{LITERATURE CITED}

Beltrando G, Cadet DL (1990) Interannual variability of the short rain season in East Africa: relationships with general atmospheric circulation. Veille Clim Satellitaire 33:19-36

Black E, Slingo J, Sperber KR (2003) An observational study of the relationship between excessively strong short rains in Coastal East Africa and Indian Ocean SST. Mon Weather Rev 131:74-94

Camberlin P, Okoola RE (2003) The onset and cessation of the 'long rains' in eastern Africa and their interannual variability. Theor Appl Climatol 75:43-54

Camberlin P, Philippon N (2002) The East African March-May rainy season: associated atmospheric dynamics and predictability over the 1968-1997 period. J Clim 15:1002-1019

Camberlin P, Wairoto J (1997) Intraseasonal wind anomalies related to wet and dry spells during the 'long' and 'short' rainy seasons in Kenya. Theor Appl Climatol 58:57-69

Cheng X, Wallace JM (1993) Cluster analysis of the northern hemisphere wintertime $500-\mathrm{hPa}$ height field: spatial patterns. J Atmos Sci 50:2674-2696

Desbois M, Sèze G, Szejwach G (1982) Automatic classification of clouds on METEOSAT imagery: application to high level clouds. J Appl Meteorol 21:401-412

Gruber A, Su X, Kanamitsu M, Schemm J (2000) The comparison of two merged rain gauge-satellite precipitation datasets. Bull Am Meteorol Soc 81:2631-2644

Hastenrath S (2000) Zonal circulations over the equatorial Indian Ocean. J Clim 13:2746-2756

Huffman GJ, Adler RF, Rudolf B, Schneider U, Keehn PR (1995) Global precipitation estimates based on a technique for combining satellite-based estimates, rain gauge analysis, and NWP model precipitation information. J Clim 8:2810-2823

Huffman GJ, Adler RF, Rudolf B, Schneider U, Keehn PR (1997) The Global Precipitation Climatology Project (GPCP) combined precipitation dataset. Bull Am Meteorol Soc 78:5-20

Huth R (1996) An intercomparison of computer-assisted circulation classification methods. Int J Climatol 16:893-922

Johnson DH, Mörth HT (1960) Forecasting research in East Africa. In: Bargman DJ (ed) Tropical meteorology in Africa. Munitalp Foundation, Nairobi, p 56-137

Kabanda TA, Jury MR (2000) Synoptic evolution of composite wet spells over Northern Tanzania. Clim Res 15:239-248

Kalnay E, Kanamitsu M, Kistler R, Collins W and 18 others (1996) The NCEP-NCAR 40 year reanalyses project. Bull Am Meteorol Soc 77:437-471

Kanamitsu M, Ebisuzaki W, Woollen J, Yang SK, Hnilo JJ, Fiorino M, Potter GL (2002) NCEP-DOE AMIP II reanalysis (R-2). Bull Am Meteorol Soc 83:1631-1643

Kiladis GN, Weickmann KM (1997) Horizontal structure and seasonality of large-scale circulations associated with submonthly tropical convection. Mon Weather Rev 125:

Editorial responsibility: Otto Kinne,

Oldendorf/Luhe, Germany
1997-2013

Madden RA, Julian PR (1971) Description of a 40-50 day oscillation in the zonal wind in the tropical Pacific. J Atmos Sci 28:702-708

Madden RA, Julian PR (1972) Description of global-scale circulation cells in the tropics with a 40-50 day period. J Atmos Sci 29:1109-1123

Madden RA, Julian PR (1994) Observations of the 40-50 day tropical oscillation-a review. Mon Weather Rev 122: 814-837

Matthews AJ (2000) Propagating mechanisms for the Madden-Julian oscillation. Q J R Meteorol Soc 126: 2637-2652

Michelangeli PA, Vautard R, Legras B (1995) Weather regimes: recurrence and quasi stationarity. J Atmos Sci 52: $1237-1256$

Moron V, Plaut G (2003) The impact of El Niño Southern Oscillation upon weather regimes over Europe and the North Atlantic during boreal winter. Int J Climatol 23:363-379

Mpeta EJ, Jury MR (2001) Intra-seasonal convective structure and evolution over tropical East Africa. Clim Res 17:83-92

Mutai CC, Ward MN (2000) East African rainfall and the tropical circulation/convection on intraseasonal to interannual timescales. J Clim 13:3915-3939

Okoola RE (1999a) A diagnostic study of the eastern Africa monsoon circulation during the northern hemisphere spring season. Int J Climatol 19:143-168

Okoola RE (1999b) Midtropospheric circulation patterns associated with extreme dry and wet episodes over equatorial Eastern Africa during the Northern Hemisphere spring. J Appl Meteorol 38:1161-1169

Saji NH, Goswami BN, Vinayachandran P, Toshio Y (1999) The dipole mode event: Indian Ocean's coupled instability phenomenon. Nature 401:360-363

Sissons J (1966) Some examples of synoptic situations that affect East Africa. Weather 21:228-231, 260-262, 298-300

Sud YC, Walker GK, Smith WE (1991) Analysis of a general circulation model simulation of the atmospheric response to the observed sea surface temperatures anomalies of January and February 1983. J Clim 4:107-115

Todd M, Washington R (1999) Circulation anomalies associated with tropical-temperate troughs in southern Africa and the southwest Indian Ocean. Clim Dyn 15:937-951

Von Storch H, Zwiers FW (1999) Statistical analysis in climate research. Cambridge University Press, Cambridge

Washington R, Todd M (1999) Tropical-temperate links in southern Africa and southwest Indian Ocean satellitederived daily rainfall. Int J Climatol 19:1601-1616

Wheeler MC, Hendon HH (2004) An all-season real-time multivariate MJO index: development of an index for monitoring and prediction. Mon Weather Rev 132:1917-1932

Zorita E, Tilya FF (2002) Rainfall variability in northern Tanzania in the March to May season (long rains) and its links to large-scale climate forcing. Clim Res 20:31-40

Submitted: February 7, 2005; Accepted: May 12, 2005

Proofs received from author(s): July 15, 2005 